\title{
The international transmission of credit bubbles: theory and policy
}

\author{
Alberto Martin and Jaume Ventura*
}

September 2015

\begin{abstract}
We live in a new world economy characterized by financial globalization, historically low interest rates, and frequent credit booms and busts. To study this world, we extend the rational-bubbles framework of Martin and Ventura (forthcoming) to include many countries and general preferences. We find that financial globalization and low interest rates create an environment that is conducive to credit bubbles. These bubbles raise world savings and generate capital flows that may not be efficient. A global planner would adopt a policy of "leaning-against-investor-sentiment", taxing credit in those times and countries where credit is excessive and subsidizing it elsewhere. An important characteristic of this policy is that it is expectationally robust, in the sense that it isolates the world economy from fluctuations in investor sentiment. This policy may be hard to implement in a decentralized fashion, though, as individual countries are unlikely to internalize the effects of their policies on the world interest rate.
\end{abstract}

JEL classification: E32, E44, O40

Keywords: financial globalization, international capital flows, sudden stops, credit bubbles, international policy coordination

\footnotetext{
* Martin: CREI and Universitat Pompeu Fabra, amartin@crei.cat. Ventura: CREI and Universitat Pompeu Fabra, jventura@crei.cat. CREI, Universitat Pompeu Fabra, Ramon Trias Fargas 25-27, 08005-Barcelona, Spain. We would like to thank Francisco Queiros for superb research assistance. We also thank Valdimir Asriyan, Pietro Reichlin and conference participants in Gertsenzee and Vienna for useful comments. We acknowledge support from the Spanish Ministry of Science and Innovation (grants ECO2011-23197), the Generalitat de Catalunya (grant 2014SGR-830 AGAUR), and the Barcelona GSE Research Network. In addition, both Martin and Ventura acknowledge support from the ERC (Consolidator Grant FP7-615651-MacroColl and Advanced Grant FP7-249588-ABEP, respectively), and Martin thanks the IMF Research Fellowship.
} 
The last twenty five years can be broadly described as a period of falling interest rates, rising financial integration and frequent credit booms and busts. Figure 1 plots the evolution of the real interest rate and of the share of countries experiencing a credit boom between 1990 and 2012. As the figure shows, the real interest rate has fallen progressively and has become negative towards the end of the sample; the share of countries experiencing a credit boom, in the meantime, has increased over time. In the run-up to the financial crisis of 2008 , almost $30 \%$ of the world's countries were experiencing a credit boom. Figure 2 plots the international financial integration (IFI) index, defined as the sum of a country's foreign assets and liabilities as a share of GDP: both the top panel, which depicts the evolution of the IFI for advanced economies, and the bottom panel, which depicts the IFI for emerging economies, reflect a substantial increase in financial integration between 1990 and 2012 .

It is tempting to view these three stylized facts as part of a general narrative, in which greater financial integration, low and declining interest rates and frequent credit booms (and busts) are different aspects of the same phenomenon. This is exactly the view that many espoused in the aftermath of the 2008 financial crisis, when it was widely argued that low interest rates in advanced economies, which resulted from excessive capital inflows, relaxed lending standards and fueled the credit boom that would eventually give rise to the crisis. ${ }^{1}$ Although appealing, this narrative raises a number of questions. What generates these low interest rates? Why should they give rise to credit booms and busts, as opposed to a permanent rise in credit? What are the welfare implications of such low interest rates? Is there a role for policy intervention and, if so, for policy coordination across countries? This paper provides an analytical framework to address these questions.

The starting point of our analysis is the model of credit bubbles that we developed in Martin and Ventura (forthcoming). The centerpiece of this model is a credit friction that limits the amount of collateral, depressing both the interest rate and investment. In this situation, shocks to investor sentiment give rise to credit bubbles, that is, expansions in credit backed by expectations of future credit. When a credit bubble appears or is created today, more funds are immediately available for investment: this is the crowding-in effect. But tomorrow some credit will be diverted away from investment to cancel today's additional credit: this is the crowding-out effect. Since bubbles appear in environments in which the interest rate is below the growth rate, this crowding-out effect declines over time. Thus, credit bubbles initially expand investment and then contract it. There is an optimal rate of bubble creation that trades off these two effects and maximizes long-run welfare.

\footnotetext{
${ }^{1}$ See, for example, Bernanke (2009a), The Economist (2009), Krugman (2009) and Portes (2009).
} 
The laissez-faire equilibrium does not always deliver this optimal rate, and this provides a new rationale for policy. In particular, welfare can be improved by taxing credit when bubble creation is too high, and subsidizing credit when bubble creation is too low.

This paper extends our earlier model in two directions. The first one is methodological, as we derive here all the results using Epstein-Zin-Weil preferences while in our previous work we focused on the special case of linear preferences. This extension allows us to explore how attitudes towards risk and intertemporal substitution affect some aspects of the analysis. In particular, we find that the main properties of the laissez-faire equilibrium remain essentially unchanged, but the welfare and policy analysis is substantially enriched. The second extension is more substantive, as we consider here a multi-country world while our original model featured a single closed economy. This allows us to study how financial integration affects the properties of credit bubbles, how the latter are transmitted across countries, and the role of international policy coordination. With the help of this extended model, we obtain new results on these problems.

The first set of results are about financial integration and its effects on credit bubbles. Assume a credit bubble appears in a given country. That is, market participants suddenly expect some lucky entrepreneurs in the country to be able to borrow more in the future. This is what we refer to as bubble creation. This change in investor sentiment provides additional collateral to the lucky entrepreneurs (i.e. expectation of future credit) and allows them to borrow more today. How does financial integration shape the country's response to this shock?

Let us start with the crowding-in effect, which operates on impact. As the lucky entrepreneurs borrow more today, the interest rate increases and the collateral of other, unlucky, entrepreneurs falls reducing their borrowing. Nonetheless, the net effect on credit and investment of the new bubble is positive on impact, and this is what we call the crowding-in effect. In a closed economy, lucky and unlucky entrepreneurs are all domestic and the entire crowding-in effect falls on domestic investment. In an open economy, some unlucky entrepreneurs are foreign. As a result, domestic investment expands by more than the crowding-in effect, while investment in other countries falls. Thus, credit bubbles have a larger positive short-run effect on domestic investment in financially integrated economies. Moreover, credit bubbles are transmitted negatively through the interest rate and reduce investment in other countries.

Let us continue with the crowding-out effect, which operates with a delay. As the lucky entrepreneurs borrow more tomorrow to pay their debts, the interest rate remains high and the collateral of unlucky entrepreneurs remains low. The credit available for investment declines, and this is the 
crowding-out effect. Once again, the importance of this crowding-out effect depends on financial integration. In the closed economy, unlucky entrepreneurs are domestic and domestic investment suffers the entire crowding-out effect. In the open economy, however, some unlucky entrepreneurs are foreign and part of the crowding-out effect is exported or shifted abroad. Thus, domestic investment falls less than the crowding-out effect, and investment in other countries declines.

One way to summarize these results is that, in financially integrated economies, credit bubbles create domestic collateral, but they also destroy foreign collateral through an increase in the interest rate. Domestic investment expands on impact by more than the crowding-in effect because part of the expansion is financed with foreign savings. Likewise, domestic investment declines with a delay by less than the crowding-out effect because part of the credit that is used to cancel initial credit is financed with foreign savings.

The second set of results are about the welfare properties of different bubbles and the role of policy. Even though some bubbles are more desirable than others, nothing guarantees that they will materialize in equilibrium. In fact, an essential feature of bubbles is that they are driven by investor sentiment or market expectations. Their value today depends on market expectations about their value tomorrow, which in turn depends on tomorrow's market expectations about their value on the day after, and so on.

Because of this, the bubble provided by the market may be either too small or too large, or it may be suboptimally distributed across countries. It may, moreover, fluctuate over time as expectations change. When a bubble pops up in a country, it leads to capital inflows and a credit boom. When the bubble bursts, however, the logic is reversed: capital leaves as the country experiences a "sudden stop" and there is a credit bust. At no point of this cycle, the return to investment plays a role in determining the direction of capital flows. If the country has high productivity and a low capital stock, the bubble improves temporarily the world allocation of capital. But if instead the country has low productivity and a high capital stock, the bubble temporarily worsens the world allocation.

In such a context, there is a role for policy. In particular, we consider the case in which countries can tax and subsidize credit contracted by their own citizens. We start by studying cooperative equilibria in which policies are chosen to maximize the weighted sum of individual utilities and therefore deliver constrained Pareto optimal allocations. This requires countries to adopt a policy of "leaning against investor sentiment", taxing credit where the rate of bubble creation is inefficiently large and subsidizing it elsewhere. This policy is what we call expectationally robust, in the sense that it stabilizes investment, output and consumption and insulates them from fluctuations in 
investor sentiment.

Although the cooperative solution provides a useful benchmark, it is not a very realistic description of the real world. Thus, we also analyze non-cooperative equilibria in which policies are the outcome of a Nash problem between all governments. Since the latter do not take into account policy externalities, non-cooperative equilibria are not in general constrained Pareto optimal. Countries tend to subsidize credit too much because they do not internalize the part of the crowding-out effect that is exported abroad.

The rest of the paper is structured as follows. Section 1 develops a multi-country model of credit bubbles. Section 2 explores bubbly equilibria in low interest rate environments and studies the implications of bubbles for the world capital stock and its geographical allocation. Section 3 studies the role of policy, characterizes constrained Pareto optimal allocations and analyzes policy choices in cooperative and non-cooperative equilibria. Section 4 concludes.

\section{Literature review:}

Our paper is closely related to three strands of literature. To begin with, it builds on the notion that financial frictions are important determinants of the size and direction of capital flows. This is related to Gertler and Rogoff (1990), Boyd and Smith (1997), Matsuyama (2004) and Aoki et al. (2010), all of which argued that contracting frictions can generate capital outflows even in capital scarce or high-productivity economies. Recently, similar models have been developed to account for global imbalances and low international interest rates. In Caballero et al. (2008), for example, high-growing developing economies may experience capital outflows due to pledgeability constraints that restrict their supply of financial assets. In Mendoza et al. (2007), it is instead the lack of insurance markets in developing economies that fosters precautionary savings and the consequent capital outflows. The major distinction between our work and this literature is that we show how the low interest rates brought about by financial frictions may give rise to asset bubbles.

In this regard, we are also close to the recent research on bubbles and financial frictions, including Farhi and Tirole (2011), Miao and Wang (2011), and our own previous work (Martin and Ventura (2011, 2012, forthcoming)). Of this literature, we are closest in interest and focus to the branch that has extended the analysis to open economies, including Caballero and Krishnamurthy (2006), Kraay and Ventura (2007), Ventura (2011), and Basco (2014).

Our paper is also related to the large body of research that studies fluctuations in credit. On the empirical front, this research has sought to identify empirical regularities of credit booms and busts: Gourinchas et al. (2001), Claessens et al. (2011), Mendoza and Terrones (2012), 
Dell'Ariccia et al. (2012) and Schularick and Taylor (2012) fall within this category. On the theoretical front, various papers have tried to model "credit cycles" as an equilibrium outcome of competition in financial markets. Some examples of this work are Ruckes (2004), Dell'Ariccia and Marquez (2006), Matsuyama (2007), Gorton and He (2008) and Martin (2008). Like us, these papers model fluctuations in credit. Unlike us, though, these papers emphasize the role of regulation or the incentives in generating and magnifying fluctuations in credit. We take instead a macroeconomic perspective and argue that low interest create the conditions for asset bubbles to arise, which may themselves give rise to credit booms and busts.

In our framework, credit booms and busts are possible due to multiple equilibria. During a boom, credit is sustained by the expectation of future credit, i.e., creditors lend to entrepreneurs today because they expect other creditors to do so in the future as well. This aspect of our paper is reminiscent of the work of Cole and Kehoe (2000), who show how a country with foreign debt may suffer from roll-over crises driven by investor sentiment: at any point in time, individual creditors may refuse to roll-over the country's debt if they expect other creditors to do so. One key difference with their work is that, in our framework, it is creditors' expectations about lending by future - as opposed to contemporaneous - creditors that matters. In this regard, our work is closer to the type of multiplicity highlighted by Alesina et al. (1992) and, more recently, by Lorenzoni and Werning (2014).

\section{A multi-country model of credit bubbles}

This section presents a multi-country model of credit bubbles that builds on the closed-economy model developed by Martin and Ventura (forthcoming). The key element of this model is a credit friction that limits the amount of collateral in the economy. As a result, the demand for credit is low and both the interest rate and investment are depressed. This creates the conditions for the economy to experience bubble-driven credit booms and busts. Extending this framework to a multi-country world allows us to study how these booms and busts affect the world stock of capital and its distribution.

\subsection{Basic setup}

We consider a world economy with many countries, indexed by $j \in J$. Time is discrete and infinite, $t=0, \ldots, \infty$. The world is populated by two-period overlapping generations that are equally sized 
and uniformly distributed across countries. All members of generation $t$ maximize the following utility function:

$$
U\left(c_{j 1 t}^{i}, c_{j 2 t+1}^{i}\right)=\frac{\left(c_{j 1 t}^{i}\right)^{1-1 / \theta}-1}{1-1 / \theta}+\beta \cdot \frac{E_{t}\left\{\left(c_{j 2 t+1}^{i}\right)^{1-\sigma}\right\}^{\frac{1-1 / \theta}{1-\sigma}}-1}{1-1 / \theta}
$$

where $c_{j 1 t}^{i}$ and $c_{j 2 t+1}^{i}$ are the consumptions of individual $i$ in country $j$ in the first and second periods of his/her life, respectively. Naturally, $c_{j 1 t}^{i} \geq 0$ and $c_{j 2 t+1}^{i} \geq 0$. The preferences in Equation (1) are often called Epstein-Zin-Weil preferences, and they are defined by three parameters: the coefficient of risk aversion, $\sigma \in(0, \infty)$; the intertemporal elasticity of substitution, $\theta \in(0, \infty)$; and the discount factor $\beta \in(0, \infty)$. The usual isoelastic case applies when the coefficient of risk aversion equals the inverse of the elasticity of intertemporal substitution, i.e. $\sigma=1 / \theta$.

The production technology takes the standard Cobb-Douglas form: $F\left(l_{j t}, k_{j t}\right)=A_{j} \cdot l_{j t}^{1-\alpha} \cdot k_{j t}^{\alpha}$ with $\alpha \in[0,1]$, where $l_{j t}$ and $k_{j t}$ denote the labor force and the capital stock in country $j$. We allow for cross-country differences in productivity, as measured by $A_{j}$. Each generation supplies one unit of labor so that $l_{j t}=1$. The capital stock depreciates in production so that $k_{j t+1}$ is both the capital stock in period $t+1$, and investment in period $t$. Competition implies that factors are paid their marginal products:

$$
w_{j t}=(1-\alpha) \cdot A_{j} \cdot k_{j t}^{\alpha} \quad \text { and } \quad r_{j t}=\alpha \cdot A_{j} \cdot k_{j t}^{\alpha-1}
$$

where $w_{j t}$ and $r_{j t}$ are the wage and rental, respectively.

Up to here, we have just described a multi-country version of the classic Diamond (1965) model of capital accumulation. Tirole (1985) extended the Diamond model by adding a market in which the young purchase bubbles from the old. Let $b_{j t}$ denote the value of all bubbles in country $j$. Some of these bubbles are old since they were started by earlier generations. Some of these bubbles are new since they have been started by the current generation. Thus, we have that:

$$
b_{j t+1}=g_{j t+1} \cdot b_{j t}+n_{j t+1}
$$

where $g_{j t+1}$ denotes the growth in the value of old bubbles, and $n_{j t+1}$ is the value of new bubbles. Free-disposal implies that $g_{j t+1} \geq 0$ and $n_{j t+1} \geq 0$. This economy does not experience technology or preference shocks, but it displays stochastic equilibria with bubble or investor sentiment shocks. 
We refer to $g_{j t}$ and $n_{j t}$ as bubble-return and bubble-creation 'shocks', respectively. We refer to the joint stochastic process governing these shocks as the 'bubble': $\left\{g_{j t}, n_{j t}\right\}_{j \in J}$ for all $t .^{2}$ We also define $h_{t}=\left\{g_{j t}, n_{j t}\right\}_{j \in J}$ as the realization of the bubble shock in period $t ; h^{t}$ as a history of bubble shocks until period $t$, i.e. $h^{t}=\left\{h_{0}, h_{1}, \ldots, h_{t}\right\}$; and $H_{t}$ as the set of all possible histories, i.e. $h^{t} \in H_{t} .{ }^{3}$ The proposed bubble must be consistent with maximization and market clearing, and it is an integral part of the description of an equilibrium.

In the Diamond and Tirole models, credit markets are local and the capital stock of each country must equal the savings of its young. Moreover, since all young are identical, there are no gains from trade in these markets and they play no role in the analysis. In Martin and Ventura (forthcoming), we kept the assumption that credit markets are local, but we created a role for domestic credit by assuming that each generation/country contains two types: savers and entrepreneurs, indexed by $i \in\{S, E\}$. Entrepreneurs can hold capital and bubbles, while savers cannot do this. We keep this distinction here, but we now allow savers and entrepreneurs of all countries to trade in a global credit market. We explain how this market works next. ${ }^{4}$

\subsection{Savers, entrepreneurs and the credit market}

The representative saver in country $j$ supplies $1-\varepsilon$ units of labor when young, saves a fraction $z_{j t}$ of his labor income, and uses it to provide credit to the representative entrepreneur. The latter offers contingent contracts that cost one and promise a contingent gross return equal to $R_{t+1}^{j}$ for all $j \in J$. Let $x_{j t}^{j^{\prime}}$ be the share of savings used by the saver of country $j$ to purchase contingent credit contracts issued by the entrepreneur of country $j^{\prime}$. Naturally, $\sum_{j^{\prime}} x_{j t}^{j^{\prime}}=1$. Then, we can write the budget constraints of the saver as follows:

$$
\begin{gathered}
c_{j 1 t}^{S}=(1-\varepsilon) \cdot w_{j t} \cdot\left(1-z_{j t}\right) \\
c_{j 2 t+1}^{S}=\sum_{j^{\prime}} R_{t+1}^{j^{\prime}} \cdot x_{j t}^{j^{\prime}} \cdot z_{j t} \cdot(1-\varepsilon) \cdot w_{j t}
\end{gathered}
$$

Equation (4) simply states that the young saver consumes a fraction of his labor income. Equation (5) contains a set of constraints, one for each possible history $h^{t+1}$, saying that the old saver

\footnotetext{
${ }^{2}$ Tirole studied bubbles with predictable returns, i.e. $E_{t} g_{j t+1}=g_{j t+1}$ for all $j$ and $t$; that had been created in the initial period, i.e. $n_{j t}=0$ for all $j$ and $t>0$. We shall not impose these restrictions here.

${ }^{3}$ All variables are therefore indexed by $h^{t}$. For instance, the capital stock in country $j$ in period $t$ depends on the particular history being considered We could be more explicit about this dependence by writing $k_{j t}\left(h^{t}\right)$. But we prefer to streamline the notation, however, and we simply write $k_{j t}$.

${ }^{4}$ In Martin and Ventura (forthcoming), we also assumed that $\sigma=\theta^{-1}=0$. We relax this assumption here.
} 
consumes the return to his portfolio. Let this return be $R_{j t+1}=\sum_{j^{\prime}} R_{t+1}^{j^{\prime}} \cdot x_{j t}^{j^{\prime}}$.

Maximization implies that:

$$
\begin{gathered}
z_{j t}=\frac{\beta^{\theta}}{\beta^{\theta}+E_{t}\left\{R_{j t+1}^{1-\sigma}\right\}^{\frac{1-\theta}{1-\sigma}}} \\
E_{t}\left\{\frac{R_{j t+1}^{-\sigma}}{E_{t} R_{j t+1}^{1-\sigma}} \cdot R_{t+1}^{j^{\prime}}\right\} \leq 1
\end{gathered}
$$

where $x_{j t}^{j^{\prime}}=0$ if the corresponding inequality in Equation (7) is strict. Equations (6) and (7) implicitly define the optimal savings and portfolio choice of the saver. Since preferences are homothetic, these choices are independent of wealth. Since all savers have access to the same menu of credit contracts, they all choose the same savings rate and portfolio composition: $z_{j t}=z_{t}$ and $x_{j t}^{j^{\prime}}=x_{t}^{j^{\prime}}$ for all $j$; and this implies that $R_{j t+1}=R_{t+1}$ for all $j$. Thus, we refer to $R_{t+1}$ as the return to the market portfolio, and to $E_{t}\left\{R_{t+1}^{1-\sigma}\right\}^{\frac{1}{1-\sigma}}$ as the risk-adjusted expected return to the market portfolio.

Equation (6) then shows that savings is increasing with this return if the intertemporal elasticity of substitution is above one, i.e. $\theta>1$. We assume this throughout, even though we occasionally comment on how the analysis changes if $\theta<1 .{ }^{5}$ Equation (7) shows that the demand for a credit contract is zero if the present discounted value of its return is less than its cost, which is one. The discount rates depend on the return to the market portfolio and the coefficient of risk aversion $\sigma$.

The representative entrepreneur in country $j$ purchases capital and bubbles during youth and finances these purchases by supplying $\varepsilon$ units of labor and selling credit contracts. Let $f_{j t}$ be the financing or funds obtained by selling credit contracts. Then, the budget constraints of the entrepreneur can be written as follows:

$$
\begin{gathered}
c_{j 1 t}^{E}=\varepsilon \cdot w_{j t}+f_{j t}-b_{j t}-k_{j t+1} \\
c_{j 2 t+1}^{E}=r_{j t+1} \cdot k_{j t+1}+b_{j t+1}-R_{t+1}^{j} \cdot f_{j t}
\end{gathered}
$$

Equation (8) says that the young entrepreneur uses his labor income and the funds raised by selling credit contracts to consume, invest and purchase bubbles. Equation (9) contains a set of constraints, one for each possible history $h^{t+1}$, saying that the old entrepreneur uses the return to capital and the proceeds from selling bubbles to pay credit contracts and consume.

\footnotetext{
${ }^{5}$ This does not imply any assumption about risk aversion, since it does not restrict $\sigma$ in any way.
} 
The credit market imposes two restrictions on the credit contracts offered by entrepreneurs:

$$
\begin{gathered}
E_{t}\left\{\frac{R_{t+1}^{-\sigma}}{E_{t} R_{t+1}^{1-\sigma}} \cdot R_{t+1}^{j}\right\}=1 \\
R_{t+1}^{j} \cdot f_{j t} \leq b_{j t+1}
\end{gathered}
$$

Equation (10) is a participation constraint and it simply says that, due to competition, the return to the credit contracts offered by the entrepreneur must equal the market return. Equation (11) contains a set of collateral constraints, one for each possible history $h^{t+1}$, saying that entrepreneurs cannot pledge the return to capital to their creditors. This crude assumption creates the sort of environment that we want to study where collateral is both scarce and bubbly. A specific institutional setup where this set of constraints applies is one in which courts can seize proceeds from the sale of assets (i.e., payments from young to old entrepreneurs in the market for bubbles), but they cannot seize output before it is distributed to workers and entrepreneurs. ${ }^{6}$

We start solving the maximization problem of the entrepreneur by noting that the funds available for consumption and investment are given by:

$$
c_{j 1 t}^{E}+k_{j t+1} \leq \varepsilon \cdot w_{j t}+\left(E_{t}\left\{\frac{R_{t+1}^{-\sigma}}{E_{t} R_{t+1}^{1-\sigma}} \cdot g_{j t+1}\right\}-1\right) \cdot b_{j t}+E_{t}\left\{\frac{R_{t+1}^{-\sigma}}{E_{t} R_{t+1}^{1-\sigma}} \cdot n_{j t+1}\right\}
$$

This expression is a direct consequence of Equations (10) and (11), and it tells us that entrepreneurs obtain funds from three sources: their wages, the purchase of existing bubbles, and the expected creation of new bubbles during old age. Regarding the purchase of bubbles, recall that the return to holding bubble $j$ is its growth rate $g_{j t+1}$. If the discounted value of this return exceeds one, the demand for this bubble would be unbounded as this allows the entrepreneur to attain unbounded consumption. If the discounted value of this return fell short of one, there would be no demand for bubble $j$ because holding it reduces the consumption attainable to the entrepreneur. Thus, equilibrium in the market for bubbles requires that the discounted value of the return to bubbles

\footnotetext{
${ }^{6}$ In Martin and Ventura (forthcoming), we studied the more general case in which entrepreneurs can also pledge a fraction of the return to capital:

$$
R_{t+1}^{j} \cdot f_{j t} \leq \phi \cdot r_{j t+1} \cdot k_{j t+1}+b_{j t+1}
$$

where $\phi \in[0,1]$. We focus here on the case $\phi=0$ for simplicity, and we refer the reader to this earlier paper for a detailed analysis of how fundamental $\left(\phi \cdot r_{j t+1} \cdot k_{j t+1}\right)$ and bubbly $\left(b_{j t+1}\right)$ collateral interact.
} 
equals one:

$$
E_{t}\left\{\frac{R_{t+1}^{-\sigma}}{E_{t} R_{t+1}^{1-\sigma}} \cdot g_{j t+1}\right\}=1
$$

for all $j$ and $t$. This not only ensures that the entrepreneur is willing to purchase existing bubbles, but it also ensures that he is able to borrow enough to finance these purchases.

We now assume that collateral constraints are always binding by focusing on equilibria in which:

$$
r_{j t+1}>R_{t+1}^{\sigma} \cdot E_{t} R_{t+1}^{1-\sigma} \text { for all } h^{t+1}
$$

for all $j$ and $t$. This condition implies that entrepreneurs always want to invest as much as possible. When all collateral constraints are binding, the entrepreneur effectively 'sells' all of his bubble to savers in the credit market and holds only capital. Since the return to his portfolio is $r_{j t+1}$, the entrepreneur is not holding any risk and he behaves as a risk-neutral agent at the margin. Since the saver is holding risk, there might be gains from transferring part of this risk to the entrepreneur. This is exactly what condition (13) rules out. If this condition failed, the entrepreneur would like to purchase bubbles that are cheap and provide a high return because they pay in histories where the return to the market portfolio is high. This case might be interesting in some context, but we rule it out here because it complicates the analysis substantially and it does not seem to affect much the results that we obtain.

If collateral constraints are binding, maximization implies that:

$$
k_{j t+1}=\frac{\beta^{\theta}}{\beta^{\theta}+r_{j t+1}^{1-\theta}} \cdot\left[\varepsilon \cdot w_{j t}+E_{t}\left\{\frac{R_{t+1}^{-\sigma}}{E_{t} R_{t+1}^{1-\sigma}} \cdot n_{j t+1}\right\}\right]
$$

Equation (14) describes the allocation of funds between consumption and investment. As in the case of savers, the share of funds that are saved and invested increase with the return to the entrepreneur's portfolio if the elasticity of intertemporal substitution is larger than one, i.e. $\theta>$ 1. Since the return to capital exceeds the risk-adjusted expected return to the market portfolio, entrepreneurs save a larger fraction of their income than savers.

Having solved the maximization problems of savers and entrepreneurs, we turn now to credit market clearing. Define $f_{t}$ and $b_{t}$ as world credit and bubble, i.e. $f_{t}=\sum_{j} f_{j t}$ and $b_{t}=\sum_{j} b_{j t}$. Since collateral constraints are binding, the return to the market portfolio must be

$$
R_{t+1}=\frac{b_{t+1}}{f_{t}}
$$


for each history $h^{t+1}$. Thus, world credit is determined and distributed as follows:

$$
\begin{gathered}
\frac{\beta^{\theta}}{\beta^{\theta}+f_{t}^{\theta-1} \cdot E_{t}\left\{b_{t+1}^{1-\sigma}\right\}^{\frac{1-\theta}{1-\sigma}}} \cdot \sum_{j}(1-\varepsilon) \cdot w_{j t}=f_{t} \\
\frac{f_{j t}}{f_{t}}=E_{t}\left\{\frac{b_{t+1}^{-\sigma}}{E_{t} b_{t+1}^{1-\sigma}} \cdot b_{j t+1}\right\}
\end{gathered}
$$

Equation (16) determines the level of world credit that is consistent with the income of savers and the collateral of entrepreneurs. If $\theta>1$, as we have assumed, credit increases with the risk-adjusted

expected value of the bubble, i.e. $E_{t}\left\{b_{t+1}^{1-\sigma}\right\}^{\frac{1}{1-\sigma}}$. Equation (17) then determines how this credit is allocated across countries. The rule is simple: each country obtains the value of its collateral, namely, the market value of its bubble next period. This completes the description of the model.

\subsection{Equilibrium dynamics}

A competitive equilibrium consists of a bubble: $\left\{g_{j t}, n_{j t}\right\}_{j \in J}$ for all $t$; and a non-negative sequence of associated state variables: $\left\{k_{j t}, b_{j t}\right\}_{j \in J}$ for all $t$; such that individuals maximize and markets clear. To construct equilibria, we propose a bubble $\left\{g_{j t}, n_{j t}\right\}_{j \in J}$ for all $t$ such that:

$$
E_{t}\left\{\frac{b_{t+1}^{-\sigma}}{E_{t} b_{t+1}^{1-\sigma}} \cdot f_{t} \cdot g_{j t+1}\right\}=1 \text { and } n_{j t+1} \geq 0
$$

for all $j$ and $t$. We then determine all possible sequences for the state variables $\left\{k_{j t}, b_{j t}\right\}_{j \in J}$ from a given initial condition using this set of equations:

$$
\begin{gathered}
b_{j t+1}=g_{j t+1} \cdot b_{j t}+n_{j t+1} \\
f_{t}=\frac{\beta^{\theta}}{\beta^{\theta}+f_{t}^{\theta-1} \cdot E_{t}\left\{b_{t+1}^{1-\sigma}\right\}^{\frac{1-\theta}{1-\sigma}}} \cdot(1-\varepsilon) \cdot(1-\alpha) \cdot \sum_{j} A_{j} \cdot k_{j t}^{\alpha} \\
k_{j t+1}=\frac{\beta^{\theta}}{\beta^{\theta}+\left(\alpha \cdot A_{j} \cdot k_{j t+1}^{\alpha-1}\right)^{1-\theta}} \cdot\left[\varepsilon \cdot(1-\alpha) \cdot A_{j} \cdot k_{j t}^{\alpha}+E_{t}\left\{\frac{b_{t+1}^{-\sigma}}{E_{t} b_{t+1}^{1-\sigma}} \cdot n_{j t+1}\right\} \cdot f_{t}\right]
\end{gathered}
$$

If all sequences generated in this way are such that $k_{j t} \geq 0$ and $b_{j t} \geq 0$ for all $j$ and $t$, the proposed bubble is an equilibrium. Otherwise, the proposed bubble is not an equilibrium.

This procedure reminds us that, to construct and interpret equilibria, we are sometimes forced to make assumptions about investor expectations. There might be some implications of the model that 
apply under any equilibrium bubble and allow us to use the model to interpret data without making further assumptions. But other implications of the model apply only in a subset of equilibrium bubbles. In this case, we must choose an equilibrium bubble before using the model to interpret data.

Once we choose an equilibrium bubble, the world economy constitutes a complete dynamic system and Equations (19)-(21) are its law of motion. From a given initial state $\left\{k_{j 0}, b_{j 0}\right\}_{j \in J}$, Equations (19)-(21) allow us to obtain the following state $\left\{k_{j 1}, b_{j 1}\right\}_{j \in J}$. Before drawing $\left\{g_{j 1}, n_{j 1}\right\}_{j \in J}$, Equations (20)-(21) determine the set of capital stocks for next period. After drawing $\left\{g_{j 1}, n_{j 1}\right\}_{j \in J}$, Equation (19) determines the set of bubbles for next period. We can then start the process again using $\left\{k_{j 1}, b_{j 1}\right\}_{j \in J}$ as the initial state to obtain $\left\{k_{j 2}, b_{j 2}\right\}_{j \in J}$. Iterating this procedure, we find the dynamics of the world economy and determine its properties.

Equilibrium bubbles must satisfy two conditions. The first one is that their growth be large enough to make the bubble attractive to buyers. This is captured by the requirement that equilibrium bubbles satisfy Equation (18). Somewhat loosely, this condition says that bubble growth must be approximately equal to the return to the market portfolio. ${ }^{7}$ The second condition is that the growth of the bubble must be small enough to not outgrow the funds available to buyers. This second condition is imposed here when we require that equilibrium bubbles be such that $k_{j t} \geq 0$ for all $j$ and $t$. Loosely speaking again, this condition says that bubble growth does not exceed the growth rate of the economy. Thus, equilibrium bubbles describe environments in which the return to the market portfolio does no exceed the growth rate of the economy.

Traditional models of bubbles generate low returns to the market portfolio by assuming that the supply of credit is too high. In these models, the limited pledgeability constraint is not binding and the return to the market portfolio equals the marginal product of capital. Thus, bubbles are a sign that the marginal product of capital is below the growth rate and the economy is overinvesting relative to the first-best allocation. Bubbles are useful in this context because they provide an alternative savings vehicle, absorbing the excess supply of credit, crowding-out capital and mitigating the overinvestment problem.

This is not the route we follow here, though. We instead generate low returns to the market portfolio by assuming that the demand for credit is too low. The limited pledgeability constraint is binding and the lack of collateral depresses the return to the market portfolio. Thus, ours is

\footnotetext{
${ }^{7}$ If bubble growth is predictable, i.e. $E_{t} g_{j t+1}=g_{j t+1}$; Equation (12) implies that $g_{j t+1}=R_{t+1}$ and this statement is exactly correct.
} 
an environment in which low returns to the market portfolio do not indicate overinvestment, but exactly the opposite. The economy is underinvesting relative to the first-best allocation because collateral is insufficient, lowering the return to the market portfolio and discouraging savings. Bubbles might be useful in this context because they provide collateral, raising the demand for credit, crowding-in capital and mitigating the underinvestment problem. ${ }^{8}$

\section{Dynamics of credit booms and busts}

The world economy developed in the previous section can experience bubble-driven credit booms and busts. Binding credit constraints make collateral and its distribution a major determinant of the world capital stock and its allocation. Bubbles affect collateral and, as a result, credit and investment. We first provide some general results about the effects of bubbles that apply in all equilibria. We then construct a sequence of equilibrium bubbles that illustrate more specifically how the model works. Despite the simplicity of the basic economic forces that this model captures, some of these equilibria display a high degree of complexity and unpredictability.

\subsection{Bubbles, credit and investment: understanding the mechanism}

We start by showing the effects of bubble creation. To do this, it is useful to unbundle Equation (21) as follows:

$$
\begin{gathered}
k_{j t+1}=\frac{\beta^{\theta}}{\beta^{\theta}+\left(\alpha \cdot A_{j} \cdot k_{j t+1}^{\alpha-1}\right)^{1-\theta}} \cdot\left[\varepsilon \cdot(1-\alpha) \cdot A_{j} \cdot k_{j t}^{\alpha}+f_{j t}-R_{t}^{j} \cdot f_{j t-1}\right] \\
f_{j t}=E_{t}\left\{\frac{R_{t+1}^{-\sigma}}{E_{t} R_{t+1}^{1-\sigma}} \cdot b_{j t+1}\right\} \quad \text { and } \quad R_{t}^{j} \cdot f_{j t-1}=b_{j t}
\end{gathered}
$$

for all $j$ and $t$. Equation (22) shows that investment is a fraction of the funds available to entrepreneurs, which consist of entrepreneurial wages plus new credit minus the repayment of past credit. Equation (23) shows that new credit equals the discounted value of the future bubble (i.e., the future collateral of entrepreneurs), while the repayment of old credit equals the present bubble

\footnotetext{
${ }^{8}$ This model contains separate markets for credit and for bubbles (there is no market for used capital, as we have assumed full depreciation). Although this is useful to preserve theoretical clarity, it may leave some readers wondering where is the market for bubbles in the real world. We think of many real-world assets, such as firms, as portfolios or bundles of capital and bubbles. This is exactly what the portfolios entrepreneurs stand for. For a more detailed discussion on real-world interpretations of the market for bubbles, see Martin and Ventura (2011, section III and forthcoming, section 1.4).
} 
(i.e., the current collateral of entrepreneurs). The larger is the future bubble, the larger is new credit and the larger are the funds available for investment. The larger is the present bubble, the larger is the repayment of past credit and the smaller are the funds available for investment.

The balance of these two effects is positive and equals the discounted value of the bubble-creation shock:

$$
f_{j t}-R_{t}^{j} \cdot f_{j t-1}=E_{t}\left\{\frac{R_{t+1}^{-\sigma}}{E_{t} R_{t+1}^{1-\sigma}} \cdot n_{j t+1}\right\}
$$

for all $j$ and $t$. A first result then is that, ceteris paribus, the larger is the discounted value of a country's bubble creation shock, the larger is country's credit and investment. We can refer to this result as the direct effect of bubble creation on credit and investment.

The "ceteris paribus" qualification in this result applies because we are holding constant the return to the market portfolio. This might be a good assumption if we are considering the effects of bubble creation in a small country. But it might fail if we consider a shock that affects a large country, or a shock that is common to many small countries. In this case, we need to determine whether bubble creation has also an indirect effect on credit and investment through the return to the market portfolio.

But it is straightforward to see that this is the case. To show this, we now unbundle Equation (20) as follows:

$$
\begin{gathered}
f_{t}=\frac{\beta^{\theta}}{\beta^{\theta}+E_{t}\left\{R_{t+1}^{1-\sigma}\right\}^{\frac{1-\theta}{1-\sigma}}} \cdot(1-\varepsilon) \cdot(1-\alpha) \cdot \sum_{j} A_{j} \cdot k_{j t}^{\alpha} \\
E_{t}\left\{R_{t+1}^{1-\sigma}\right\}^{\frac{1}{1-\sigma}} \cdot f_{t}=E_{t}\left\{\left(\sum_{j} g_{j t+1} \cdot b_{j t}+n_{j t+1}\right)^{1-\sigma}\right\}^{\frac{1}{1-\sigma}}
\end{gathered}
$$

Equations (25)-(26) can be interpreted as the demand and supply of credit, respectively. Equation (25) shows that the supply of credit is increasing with the risk-adjusted expected return to the market portfolio. This follows from our assumption that $\theta>1$, which ensures that savings responds positively to asset returns. Equation (26) shows that, for given $b_{j t}$ and $n_{j t+1}$, the demand for credit is instead declining with the return to the market portfolio. The lower is this return, the larger is the discounted value of collateral and the less binding are credit constraints.

It follows from Equations (25)-(26) that bubble creation raises the demand for credit and this increases the risk-adjusted expected return. Thus, the indirect effect of bubble-creation shocks is negative. The combination of direct and indirect effects is always positive, however, and we can conclude that bubble creation shocks raise credit and investment. In earlier research, we have 
labeled this combination of direct and indirect effects as the crowding-in effect of bubbles.

From a country perspective, the crowding-in effect is stronger with a global credit market than with a local one. In the latter case, both the direct and indirect effects of a bubble creation shock stay at home. Since these effects have different signs, this attenuates fluctuations in credit and investment. In the case of a global credit market, the direct effect of a bubble creation shock still stays at home, but the indirect effect is mostly exported through the credit market. This means that bubble creation shocks have larger domestic effects on credit and investment with a global credit market. It also means that bubble creation shocks are transmitted negatively to other countries, as the increase in the risk-adjusted return lowers credit and investment in the rest of the world.

One can think of the crowding-in effect as describing the short-run or impact effect of bubble creation. But creating bubbles today leads to higher bubbles tomorrow. Indeed, the value of today's bubble is somehow the result of all past bubble creation and, as Equation (26) shows, today's bubble $b_{j t}$ raises the demand for credit and the risk-adjusted expected return. Thus, the indirect effect of bubble creation stays well after the direct effect has disappeared. In earlier research, we labeled this negative delayed effect of bubble creation as the crowding-out effect of bubbles.

From a country perspective, the crowding-out effect is smaller with a global credit market than with a local one. The intuition is the same as before. Past bubble creation, embodied in the current bubble, raises the risk-adjusted expected return and lowers credit and investment. With a local credit market, this effect stays at home. With a global credit market, this effects is exported abroad.

The discussion above points to a crucial aspect of the relationship between credit, investment and bubbles. Credit in our economy is backed by bubbles, but not all credit is used to invest. Credit backed by bubbles that have been created in the past is used to purchase these same bubbles. It is credit backed by expected bubble creation in the future that is used to invest. This explains why bubble creation is always expansionary on impact. Whether bubble creation is expansionary or contractionary in the long run depends on the strength of the crowding-out effect. In some equilibria, one of the effects always dominates. In some other equilibria, the one effect dominates sometimes, while the other dominates some other times. We shall see some examples shortly that clarify the conditions that determine this.

So far, we have focused on bubble creation shocks. But this world economy also experiences bubble-return shocks. This second type of shocks change the value of the bubble. Positive bubblereturn shocks raise the value of the bubble, thereby exacerbating the crowding-out effect of previous 
bubble-creation shocks. Negative bubble-return shocks instead lower the value of the bubble, mitigating the crowding-out effect of previous bubble-creation shocks. In short, the growth of old bubbles increases credit but it reduces the amount of it that ends up in investment.

\subsection{Some examples}

Perhaps the best way to see all these effects at work is through a series of simple examples. The first one considers a bubble for which the bubble-return and bubble-creation shocks are zero for all $j$ and $t$ :

Example 1 Let $\left\{g_{j t+1}, n_{j t+1}\right\}_{j \in J}=\{0,0\}_{j \in J}$ for all $t$.

This example, which we refer to as the bubbleless equilibrium, implies that

$$
b_{j t}=0
$$

for all $j$ and $t$. The return to investment is positive, but entrepreneurs do not have any collateral. As a result, the credit market effectively shuts down: $f_{j t}=0$ and $R_{t+1}^{j}=0$; and there is no credit available for investment:

$$
E_{t}\left\{\frac{R_{t+1}^{-\sigma}}{E_{t} R_{t+1}^{1-\sigma}} \cdot n_{j t+1}\right\}=0
$$

for all $j$ and $t$. Since the return to the market portfolio collapses to zero, savers choose to consume all their labor income during youth. ${ }^{9}$ Thus, capital accumulation must be financed entirely with the savings of domestic entrepreneurs. The dynamics of the world distribution of capital stocks is determined as follows:

$$
k_{j t+1}=\frac{\beta^{\theta}}{\beta^{\theta}+\left(\alpha \cdot A_{j} \cdot k_{j t+1}^{\alpha-1}\right)^{1-\theta}} \cdot \varepsilon \cdot(1-\alpha) \cdot A_{j} \cdot k_{j t}^{\alpha}
$$

for all $j$ and $t$. Recall that $\varepsilon$ is the fraction of wages which is already in the hands of entrepreneurs and needs not be intermediated through the credit market. In the limit $\varepsilon \rightarrow 1$, the credit market is irrelevant and the bubbleless equilibrium is nothing but the textbook version of the Diamond model. In the limit $\varepsilon \rightarrow 0$, the credit market is essential and the bubbleless equilibrium breaks down.

\footnotetext{
${ }^{9}$ If $\theta<1$, as the return to the market portfolio approaches zero, the savings rate approaches one and not zero.
} 
The absence of a well-functioning credit market creates two inefficiencies. The first one is that world savings are too low, as savers cannot find assets to purchase and are forced to consume early. As a result, the world capital stock is too low. The second inefficiency is that world savings are misallocated, as entrepreneurs with high return to investment cannot bid for funds and are forced to invest only their own savings. As a result, the world capital stock is misallocated.

This misallocation is temporary, though. From any initial condition, the world economy monotonically converges to a steady state in which:

$$
\begin{gathered}
k_{j}^{*}=\left(\frac{\alpha \cdot A_{j}}{r^{*}}\right)^{\frac{1}{1-\alpha}} \\
\frac{\alpha}{r^{*}}=\frac{\beta^{\theta}}{\beta^{\theta}+r^{* 1-\theta}} \cdot \varepsilon \cdot(1-\alpha)
\end{gathered}
$$

for all $j$ and $t$. In this steady state, all countries have the same return to investment, i.e. $r_{j}^{*}=r^{*}$ for all $j$. The capital stock remains too low in the long run if this common return is above one and the economy is dynamically efficient. We assume this in what follows. ${ }^{10}$

The bubbleless equilibrium provides a useful benchmark to study the effects of bubbles on economic activity. The next example considers a bubble such that bubble-return shocks are common and constant across countries and bubble-creation shocks are such that future bubbles are proportional to economic size in all countries:

Example $2 \operatorname{Let}\left\{g_{j t+1}, n_{j t+1}\right\}_{j \in J}=\left\{g, g \cdot\left(\frac{\beta^{\theta}}{\beta^{\theta}+g^{1-\theta}} \cdot(1-\varepsilon) \cdot(1-\alpha) \cdot A_{j} \cdot k_{j t}^{\alpha}-b_{j t}\right)\right\}_{j \in J}$ for all $t$.

The key assumption in this example is that bubbles are proportional to economic size, as measured by output, in all countries:

$$
\frac{b_{j t+1}}{g}=\frac{\beta^{\theta}}{\beta^{\theta}+g^{1-\theta}} \cdot(1-\varepsilon) \cdot(1-\alpha) \cdot A_{j} \cdot k_{j t}^{\alpha},
$$

for all $j$ and $t$. Since these bubbles are deterministic, the return to the market portfolio is riskless and equal to the growth rate of old bubbles, i.e. $R_{t+1}=g$. Note moreover that the discounted value of the bubble, and thus credit in country $j \in J$, is exactly equal to the country's domestic savings. In these equilibria, therefore, all credit stays at home and there are no capital flows.

\footnotetext{
${ }^{10} \mathrm{~A}$ sufficient (but not necessary) condition ensuring this is that $\alpha>\frac{\varepsilon}{1+\varepsilon}$.
} 
The discounted value of bubble creation in country $j \in J$, and thus the amount of credit available for investment, equals:

$$
E_{t}\left\{\frac{R_{t+1}^{-\sigma}}{E_{t} R_{t+1}^{1-\sigma}} \cdot n_{j t+1}\right\}=\frac{\beta^{\theta} \cdot(1-\varepsilon) \cdot(1-\alpha)}{\beta^{\theta}+g^{1-\theta}} \cdot A_{j} \cdot k_{j t}^{\alpha}-b_{j t}
$$

The bubbleless equilibrium applies as the limiting case $g \rightarrow 0$ (and therefore $b_{j t} \rightarrow 0$ too).

It can be shown in this example that, from any initial condition, the distribution of capital stocks converges to a steady state in which:

$$
\begin{gathered}
k_{j}^{*}=\left(\frac{\alpha \cdot A_{j}}{r^{*}}\right)^{\frac{1}{1-\alpha}} \\
\frac{\alpha}{r^{*}}=\frac{\beta^{\theta}}{\beta^{\theta}+r^{* 1-\theta}} \cdot(1-\alpha) \cdot\left(\varepsilon+\frac{\beta^{\theta}}{\beta^{\theta}+g^{1-\theta}} \cdot(1-\varepsilon) \cdot(1-g)\right)
\end{gathered}
$$

for all $j$ and $t$. In this steady state, as in the previous example, the marginal product of capital is equalized across countries. Also as in the previous example, this happens because the proportion of output that is invested is constant across countries. Relative to the previous example, though, the bubble now sustains credit thereby transferring resources from current consumption to investment.

This example provides a simple illustration of the general effects of bubble creation discussed in the previous section. Equation (35), which is this example's steady state version of Equation (22), says that the stock of capital is proportional both to entrepreneurial wages and to the discounted value of bubble creation. In the long-run, this discounted value is non-monotonic in $g$. On the one hand, a higher $g$ raises aggregate savings and the supply of credit. On the other hand, a higher $g$ also raises the share of this credit that is used to purchase existing bubbles. On net, these two forces imply that the long-run discounted value of bubble creation, and thus the capital stock, is maximized at an interior interest rate $g^{*} \in(0,1) .{ }^{11}$ We shall return to this point in the policy analysis of section 3 .

The global bubble need not be constant, however, and it can vary to fuel credit booms and busts like the ones mentioned in the introduction. To show this, we combine our previous examples

\footnotetext{
${ }^{11}$ Formally, $g^{*}$ is implicitly defined as

$$
\frac{1}{\theta-1} \cdot \frac{\beta^{\theta}+g^{* 1-\theta}}{g^{*-\theta}}=1-g^{*}
$$
}


as follows:

Example 3 Let the world economy be in one of two states $m_{t+1} \in\{F, B\}$ in any period $t+1: a$ fundamental state $F$, in which $\left\{g_{j t+1}, n_{j t+1}\right\}_{j \in J}=\{0,0\}_{j \in J}$, and a bubbly episode $B$, in which

$$
\left\{g_{j t+1}, n_{j t+1}\right\}_{j \in J}=\left\{g, g \cdot\left(\frac{\beta^{\theta}}{\beta^{\theta}+(1-\pi)^{\frac{1-\theta}{1-\sigma}} \cdot g^{1-\theta}} \cdot(1-\varepsilon) \cdot(1-\alpha) \cdot A_{j} \cdot k_{j t}^{\alpha}-b_{j t}\right)\right\}_{j \in J} .
$$

The economy starts in one of the two states and transitions between them with probability $\pi<0.5$.

This example studies bubble-driven global credit booms and busts. The formulas are basically the same as before except that, even though the bubble grows at rate $g$ during the bubbly episode, the (risk adjusted) expected return to the market portfolio is $(1-\pi)^{\frac{1}{1-\sigma}} \cdot g$. In the fundamental state, this return is instead $\pi^{\frac{1}{1-\sigma}} \cdot g$. Both returns reflect the risk of investing in the global bubble, which has a positive return only with probability $1-\pi$ during a bubbly episode and with probability $\pi$ in the fundamental state.

The discounted value of bubble creation in country $j \in J$, and thus the amount of credit available for investment, equals:

$$
E_{t}\left\{\frac{R_{t+1}^{-\sigma}}{E_{t} R_{t+1}^{1-\sigma}} \cdot n_{j t+1}\right\}=\left\{\begin{array}{cc}
\frac{\beta^{\theta} \cdot(1-\varepsilon) \cdot(1-\alpha)}{\beta^{\theta}+\left((1-\pi)^{\frac{1}{1-\sigma}} \cdot g\right)^{1-\theta}} \cdot A_{j} \cdot k_{j t}^{\alpha}-b_{j t} & \text { if } m_{t}=B \\
\frac{\beta^{\theta} \cdot(1-\varepsilon) \cdot(1-\alpha)}{\beta^{\theta}+\left(\pi^{\frac{1}{1-\sigma}} \cdot g\right)^{1-\theta}} \cdot A_{j} \cdot k_{j t}^{\alpha} & \text { if } m_{t}=F
\end{array}\right.
$$

This expression shows that there are two reasons for which investment varies across states. First, the crowding-in effect of bubbles is higher during bubbly episodes, because the bubble's higher rate of return raises savings and thus total credit: all else equal, this effect expands investment. ${ }^{12}$ The crowding-out effect of bubbles is also larger during bubbly episodes, however, since a fraction of total credit is used to purchase the existing bubble $b_{j t}$ : this effect reduces investment during bubbly episodes.

Equation (36) shows that, initially, global credit as well as investment expand when the economy transitions from a fundamental to a bubbly state. When a bubbly episode starts, entrepreneurs expand their borrowing and credit, and investment and the risk-adjusted expected return rise.

\footnotetext{
${ }^{12}$ Note that, although it may be small, bubbles also have a crowding-in effect when the economy is in the fundamental state. The reason is that savers lend to entrepreneurs against the possibility that the economy transitions to a bubbly state in the future.
} 
Because the distribution of the global bubble across countries is proportional to local savings in this example, investment and savings grow at the same rate in all countries and there are no capital flows. As time passes and the economy stays in the bubbly state, though, the bubble grows and its crowding-out effect becomes stronger: eventually, it is possible for this effect to offset the crowding-in effect altogether, in which case output falls below what it would be in the fundamental state. ${ }^{13}$ Naturally, when the bubble collapses, these effects are reversed as entrepreneurs are forced to deleverage.

These examples shed light on one of the features of bubbles, i.e., they create collateral and destroy collateral thereby affecting global credit and investment. However, they say nothing about a second important feature of bubbles: they reallocate resources across countries. We illustrate this through our last example.

Example 4 Let the world economy be divided into $Q$ regions of equal size, respectively, where $J_{q}$ denotes the set of countries in region $q$. In any given period $t+1$, there are two possible states $m_{t+1} \in\{F, B\}:$ a fundamental state $F$, in which $\left\{g_{j t+1}, n_{j t+1}\right\}_{j \in J}=\{0,0\}_{j \in J}$, and; a bubbly episode $B$, during which

$\left\{g_{j t+1}, n_{j t+1}\right\}_{j \in J_{z}}=\left\{g, g \cdot\left(\eta_{j t} \cdot \frac{\beta^{\theta}}{\beta^{\theta}+(1-\pi)^{\frac{1-\theta}{1-\sigma}} \cdot g^{1-\theta}} \cdot(1-\varepsilon) \cdot(1-\alpha) \cdot \sum_{j} A_{j} \cdot k_{j t}^{\alpha}-b_{j t}\right)\right\}_{j \in J_{z}}$ in some region $z \in Q$, with $\eta_{j t+1}=\frac{A_{j} \cdot k_{j t}^{\alpha}}{\sum_{j \in J_{q}} A_{j} \cdot k_{j t}^{\alpha}}$, and $\left\{g_{j t+1}, n_{j t+1}\right\}_{j \in J_{q}}=\{0,0\}_{j \in J_{q}}$ for $q \neq z$. Ex ante, a bubbly episode is equally likely to arise in any of the world's regions. The economy starts in one of the two states and transitions between them with probability $\pi<0.5$.

This last example studies bubbly episodes that affect only a subset of countries. As such, they not only influence the level of entrepreneurial collateral in the global economy, but also its distribution across countries. Now, the risk-adjusted expected return is still $(1-\pi)^{\frac{1}{1-\sigma}} \cdot g$ during the bubbly episode, but it equals only $\pi^{\frac{1}{1-\sigma}} \cdot \frac{g}{Q}$ in the fundamental state. This return is lower than in our previous example because now bubble creation is restricted to region $z$ at the start of a bubbly episode.

\footnotetext{
${ }^{13}$ This possibility is strongest when $\pi$ is close to 0.5 .
} 
The discounted value of bubble creation in country $j \in J$, and thus the amount of credit available for investment, equals:

$$
E_{t}\left\{\frac{R_{t+1}^{-\sigma}}{E_{t} R_{t+1}^{1-\sigma}} \cdot n_{j t+1}\right\}= \begin{cases}\eta_{j t} \cdot \frac{\beta^{\theta} \cdot(1-\varepsilon) \cdot(1-\alpha)}{\beta^{\theta}+(1-\pi)^{\frac{1-\theta}{1-\sigma}} \cdot g^{1-\theta}} \cdot \sum_{j} A_{j} \cdot k_{j t}^{\alpha}-b_{j t} & \text { if } m_{t}=B \text { and } j \in J_{z} \\ 0 & \text { if } m_{t}=B \text { and } j \notin J_{z} \\ \frac{\beta^{\theta} \cdot(1-\varepsilon) \cdot(1-\alpha)}{\beta^{\theta}+\pi^{\frac{1-\theta}{1-\sigma}} \cdot\left(\frac{g}{Q}\right)^{1-\theta}} \cdot A_{j} \cdot k_{j t}^{\alpha} & \text { if } m_{t}=F\end{cases}
$$

This expression is analogous to that of the previous example, with one caveat: now the behavior of investment differs across the bubbly and the non-bubbly regions. In the bubbly region, investment rises at the beginning of a bubbly episode but it may eventually start to decline. In non-bubbly regions, investment falls unambiguously from the onset of a bubbly episode. The reason is that, in the fundamental state, all regions can sustain some credit in the expectation that they will become bubbly: once the bubbly episode is realized, though, this collateral disappears in all but one region.

When a bubbly episodes starts, entrepreneurs in the bubbly region expand their borrowing. This expansion in borrowing more than compensates for the fall in collateral and credit in the nonbubbly regions. As a consequence, the global demand for credit expands, raising the risk-adjusted return and savings in all countries: as in the previous example, then, bubbly episodes reallocate resources from consumption to investment. Differently from the previous example, though, there is now also an additional geographical reallocation effect as bubbly episodes reallocate investment across countries. In particular, the credit and investment boom of the bubbly region is partially financed through an inflow of savings from abroad, so that the region runs a current account deficit that is matched by a surplus in the rest of the world. When the bubbly episode ends, the disappearance of collateral leads to a fall in the demand of credit and to a collapse in capital flows.

There are two interesting aspects of this example. First, it illustrates how, by providing collateral, bubbles can fuel financial integration. During bubbly episodes, capital flows are high despite the lack of enforcement institutions that would make it possible for entrepreneurs to pledge their capital income: in a very exact sense, these capital flows are sustained only by expectations of future capital flows. When these episodes end though, the collateral sustaining these flows disappears and financial integration is undone as the bubbly region experiences a "sudden stop". Second, there is no guarantee that this type of financial integration will reallocate resources to their more productive uses. Recall that regions differ according to their productivity. Thus, a bubbly episode in a 
low-productivity region reallocates credit and investment inefficiently, potentially reducing global output despite fueling financial integration. ${ }^{14}$

Overall, these examples show that a world economy characterized by low interest rates can experience rich and volatile patterns of credit, capital flows, and economic activity. Moreover, even though different bubbles have different implications for welfare, it is not possible to determine whether the market will select any specific one over the rest. Thus, sometimes global credit may be too small, leading to weak investment and growth. At other times, the global credit may be too large, diverting resources from investment and this also undermines investment growth. Finally, the global bubble may be inefficiently distributed across countries, sustaining too much credit in some countries and too little in others. These observations raise a natural and important question: can policies be used to improve upon the laissez-faire equilibrium? If so, is their a role for policy coordination across countries? We turn to these questions next.

\section{Managing credit booms and busts}

This section considers the problem of governments that can influence credit markets by taxing and/or subsidizing entrepreneurs. We first describe the set of policies that we consider and show how they affect the evolution of credit, investment and output. We then characterize a type of cooperative policies, in which all governments jointly maximize a measure of global welfare, and non-cooperative policies, in which each government designs policy independently of one another.

Before turning to the analysis, though, it is important to ponder briefly on what it means to design policy in our environment. In a laissez-faire equilibrium, we need to make assumptions about investor sentiment or expectations. That is, we need to choose the bubble: $\left\{g_{j t}, n_{j t}\right\}_{j \in J}$ for all $j$ and $t$. This poses a problem for policy design, since the implementation of a policy may influence investor sentiment and "change" the bubble. We go around this problem by focusing on policies that are expectationally robust, in the sense that they implement the same allocations regardless of investor sentiment or the bubble.

\footnotetext{
${ }^{14}$ In this simple example, there is a negative correlation of output in the the bubbly and non-bubbly regions during a bubbly episode. This feature, which is not specific to bubble shocks and would also arise under local productivity shocks in our model, may seem at odds with empirical evidence. There are different ways in which the framework can be modified to generate a positive correlation of output across regions. One such modification, which we explored in earlier versions of the paper, is to introduce terms-of-trade effects. If different regions produce differentiated goods, then the non-bubbly regions will see an improvement of their terms-of-trade as their output contracts. If this effect is sufficiently strong, it is possible for output to expand in all of the world's regions in response to a local bubbly episode. We have omitted differentiated goods and terms-of-trade effects from the current version of the paper in order to preserve tractability.
} 


\subsection{What can governments do?}

We introduce governments and assume that they can influence the equilibrium allocation by subsidizing and/or taxing their entrepreneurs. In particular, the government of country $j$ promises to give its entrepreneurs of generation $t$ a transfer equal to $s_{j t+1}$ units of the consumption good during old age. These transfers can be negative and/or contingent on the state of the economy. Whenever this transfer is positive, the government of $j$ finances it by imposing a tax on the country's young entrepreneurs of generation $t+1$. If a transfer is negative, its benefit is distributed to young entrepreneurs of generation $t+1$.

These policies can be thought of as credit management policies. There are many ways to define them, but we choose one that will help clarify the analysis that follows. In particular, we define a policy as a stochastic process: $\left\{g_{j t}^{s}, n_{j t}^{s}\right\}_{j \in J}$ for all $t$ such that:

$$
s_{j t+1}=g_{j t+1}^{s} \cdot s_{j t}+n_{j t+1}^{s} .
$$

where $E_{t}\left\{\frac{R_{t+1}^{-\sigma}}{E_{t} R_{t+1}^{1-\sigma}} \cdot g_{j t+1}^{s}\right\}=1$. This allows us to interpret $E_{t}\left\{\frac{R_{t+1}^{-\sigma}}{E_{t} R_{t+1}^{1-\sigma}} \cdot n_{j t+1}^{s}\right\}$ as the net resources that the policy provides to the entrepreneur of generation $t$ in country $j$, i.e., the difference between the present value of subsidies that will be obtained in old age and the taxes paid in young age. This difference can be positive or negative.

What are the effects of a given set of policies on the equilibrium of the world economy? Since subsidies and taxes are received and paid by entrepreneurs, these policies have no direct effect on savers and their behavior is still described by Equations (6)-(7). But the policies do affect the problem of entrepreneurs, since their budget constraints are now given by,

$$
\begin{gathered}
c_{j 1 t}=\varepsilon \cdot w_{j t}+f_{j t}-k_{j t+1}-b_{j t}-s_{j t} \\
c_{j 2 t+1}=r_{j t+1} \cdot k_{j t+1}+b_{t+1}+s_{j t+1}-R_{t+1}^{j} \cdot f_{j t}
\end{gathered}
$$

Equations (38) and (39) show how the policy affects the consumption of the entrepreneur: she must finance it by paying taxes $s_{j t}$ during youth, but she also benefits from it by receiving a transfer $s_{j t+1}$ during old age. Finally, the credit market imposes two restrictions on the contracts offered by entrepreneurs. They must still satisfy the participation constraint of Equation (10) and, as long as the transfers prescribed by the policy are pledgeable to creditors, entrepreneurial contracts must 
satisfy the following set of collateral constraints:

$$
R_{t+1}^{j} \cdot f_{j t} \leq b_{j t+1}+s_{j t+1}
$$

As before, we focus throughout on equilibria in which the collateral constraints of entrepreneurs bind, i.e., equilibria that satisfy Equation (13) for all $j$ and $t$. In these equilibria, entrepreneurs choose bubble holdings so as to maximize the funds available for consumption and investment. Taking into account the budget and borrowing constraints of Equations (38)-(40), these funds are given by

$c_{j 1 t}^{E}+k_{j t+1}=\varepsilon \cdot w_{j t}+E_{t}\left\{\frac{R_{t+1}^{-\sigma}}{E_{t} R_{t+1}^{1-\sigma}} \cdot\left(g_{j t+1} \cdot b_{j t}+g_{j t+1}^{s} \cdot s_{j t}\right)\right\}-b_{j t}-s_{j t}+E_{t}\left\{\frac{R_{t+1}^{-\sigma}}{E_{t} R_{t+1}^{1-\sigma}} \cdot\left(n_{j t+1}+n_{j t+1}^{s}\right)\right\}$

A quick inspection of this expression reveals that entrepreneurial demand for bubbles remains unaffected by the policies and it is still captured by Equation (12). Taking this into account, entrepreneurial investment is now given by:

$$
k_{j t}=\frac{\beta^{\theta}}{\beta^{\theta}+r_{j t+1}^{1-\theta}} \cdot\left(\varepsilon \cdot w_{j t}+E_{t}\left\{\frac{R_{t+1}^{-\sigma}}{E_{t} R_{t+1}^{1-\sigma}} \cdot\left(n_{j t+1}+n_{j t+1}^{s}\right)\right\}\right)
$$

Equation (41) shows how this type of credit management policy affects the investment of entrepreneurs. Whenever the policy raises entrepreneurial wealth, i.e., whenever the present value of the subsidies that a generation expects to receive during old age exceeds the taxes that it must pay during youth, the policy relaxes the entrepreneurial borrowing constraint and raises investment. Whenever the policy lowers entrepreneurial wealth, it instead tightens the borrowing constraint and reduces investment.

To close the model, we just need to determine how these policies affects the competitive equilibrium of the world economy. They clearly have no direct effect on factor markets and, since they do not affect entrepreneurs' demand for bubbles, they have no direct effect on the market for bubbles. By affecting entrepreneurs' ability to borrow, though, the policies do affect the credit market, where the equilibrium conditions are now given by:

$$
\frac{\beta^{\theta}}{\beta^{\theta}+f_{t}^{\theta-1} \cdot E_{t}\left\{\left(b_{t+1}+s_{t+1}\right)^{1-\sigma}\right\}^{\frac{1-\theta}{1-\sigma}}} \cdot \sum_{j}(1-\varepsilon) \cdot w_{j t}=f_{t},
$$




$$
\frac{f_{j t}}{f_{t}}=E_{t}\left\{\frac{\left(b_{t+1}+s_{t+1}\right)^{-\sigma}}{E_{t}\left\{\left(b_{t+1}+s_{t+1}\right)^{1-\sigma}\right\}} \cdot\left(b_{j t+1}+s_{j t+1}\right)\right\},
$$

for $s_{t+1}=\sum_{j} s_{j t+1}$. Equation (42) is the market clearing condition and it says that the global supply of credit by savers equals the global demand of credit by entrepreneurs. Note, from Equations (40) and (41), that policy interventions affect this market clearing condition both through their effect on the supply of credit (via the capital stock, and thus wages) and on the demand of credit (via the collateral of entrepreneurs). Equation (43) says that global credit is allocated across countries according to the market value of their collateral, which now includes bubbles and subsidies.

To construct equilibria, we now propose a bubble: $\left\{g_{j t}, n_{j t}\right\}_{j \in J}$ for all $t$; and a policy: $\left\{g_{j t}^{s}, n_{j t}^{s}\right\}_{j \in J}$ for all $t$ such that:

$$
\begin{gathered}
E_{t}\left\{\frac{\left(b_{t+1}+s_{t+1}\right)^{-\sigma}}{E_{t}\left\{\left(b_{t+1}+s_{t+1}\right)^{1-\sigma}\right\}} \cdot f_{t} \cdot g_{j t+1}\right\}=1 \text { and } n_{j t+1} \geq 0 \\
E_{t}\left\{\frac{\left(b_{t+1}+s_{t+1}\right)^{-\sigma}}{E_{t}\left\{\left(b_{t+1}+s_{t+1}\right)^{1-\sigma}\right\}} \cdot f_{t} \cdot g_{j t+1}^{s}\right\}=1
\end{gathered}
$$

for all $j$ and $t$. We then determine all possible sequences for the state variables $\left\{k_{j t}, b_{j t}, s_{j t}\right\}_{j \in J}$ from a given initial condition using this set of equations:

$$
\begin{gathered}
b_{j t+1}=g_{j t+1} \cdot b_{j t}+n_{j t+1} \\
s_{j t+1}=g_{j t+1}^{s} \cdot s_{j t}+n_{j t+1}^{s} \\
\frac{\beta^{\theta}}{\beta^{\theta}+f_{t}^{\theta-1} \cdot E_{t}\left\{\left(b_{t+1}+s_{t+1}\right)^{1-\sigma}\right\}^{\frac{1-\theta}{1-\sigma}}} \cdot(1-\varepsilon) \cdot(1-\alpha) \cdot \sum_{j} A_{j} \cdot k_{j t}^{\alpha}=f_{t} \\
k_{j t+1}=\frac{\beta^{\theta}}{\beta^{\theta}+\left(\alpha \cdot A_{j} \cdot k_{j t+1}^{\alpha-1}\right)^{1-\theta}} \cdot\left[\varepsilon \cdot(1-\alpha) \cdot A_{j} \cdot k_{j t}^{\alpha}+E_{t}\left\{\frac{\left(b_{t+1}+s_{t+1}\right)^{-\sigma}}{E_{t}\left(b_{t+1}+s_{t+1}\right)^{1-\sigma}} \cdot\left(n_{j t+1}+n_{j t+1}^{s}\right)\right\} \cdot f_{t}\right]
\end{gathered}
$$

If all sequences generated in this way are such that $k_{j t} \geq 0$ and $b_{j t} \geq 0$ for all $j$ and $t$, the proposed bubble and policy constitute an equilibrium.

Equations (48)-(49) are key to understand the role of policy in our model. A comparison with the corresponding Equations (20)-(21) of the baseline model reveals that all the effects of policies 
$\left\{g_{j t}^{s}, n_{j t}^{s}\right\}_{j \in J}$ for all $t$ on the competitive equilibrium can be reduced to one: they replace $b_{j t}$ with $b_{j t}+s_{j t}$; and $n_{j t}$ with $n_{j t}+n_{j t}^{S}$ in both equations.

An immediate implication of this observation is that it is possible to design policies that implement the allocations of any laissez-faire equilibrium. Suppose, for instance, that governments want to implement the allocation of a desired laissez-faire equilibrium with bubble $\left\{\bar{g}_{j t}, \bar{n}_{j t}\right\}_{j \in J}$ for all t. To do so, they simply need to follow policies that are contingent on the evolution of the bubble. This leads immediately to the following proposition:

Proposition 1 Suppose that the government of country $j \in J$ can subsidize its entrepreneurs by giving them transfers $s_{j t}$ during old age. Suppose moreover that each government finances these transfers by taxing its young entrepreneurs. Then, any laissez-faire equilibrium with bubble $\left\{\bar{g}_{j t}, \bar{n}_{j t}\right\}_{j \in J}$ for all $t$ can be replicated by a policy $\left\{g_{j t}^{s}, n_{j t}^{s}\right\}_{j \in J}$ such that

$$
\begin{gathered}
n_{j t}^{s}=\bar{n}_{j t}-n_{j t} \\
g_{j t}^{s} \cdot s_{j t}=\bar{g}_{j t} \cdot \bar{b}_{j t}-g_{j t} \cdot b_{j t}
\end{gathered}
$$

for all $j$ and $t$.

Proof. Follows from previous discussion.

Proposition 1 tells us that governments seeking to replicate the allocations of a desired laissezfaire equilibrium should follow a policy of "leaning against investor sentiment". In countries and times where the bubble is low relative to the desired benchmark, the policy requires the corresponding government to subsidize credit. In countries and times where the bubble is high relative to the desired benchmark, the policy requires the corresponding government to tax credit. A salient feature of such policies is that they are expectationally robust, in the sense that they implement the allocations of the desired laissez-faire equilibrium regardless of investor sentiment. That is, these policies do not target asset prices, but instead insulate the economy from their fluctuations.

\subsection{What should governments do?}

Proposition 1 tells us how, by using the type of credit management policies that we consider, governments can in principle replicate any equilibrium bubble that they desire. Building on this result, we assume in what follows that governments directly choose their preferred bubbles $\left\{g_{j t}, n_{j t}\right\}_{j \in J}$, 
with the understanding that - in the backgroung - they are really complementing the laissez-faire equilibrium bubbles with the appropriate subsidies and taxes.

To determine which bubbles governments actually want to implement, though, we need to define both their objective functions and the equilibrium concept. Since our economy is populated by riskaverse individuals and the only source of uncertainty is investor sentiment, we focus throughout on deterministic allocations in which bubbles $\left\{g, n_{j}\right\}_{j \in J}$ are constant. One feature of these allocations is that, as in our deterministic example of section 2 , the return to the market portfolio is riskless and equal to the growth rate of old bubbles, i.e. $R_{t+1}=g$. We thus refer to $g$ as the interest rate. Another feature of these allocations is that the wage, the rate of return to capital and the capital stock depend only on the country's discounted value of bubble creation:

$$
\begin{aligned}
w_{j} & =(1-\alpha) \cdot A_{j} \cdot k_{j}^{\alpha} \\
r_{j} & =\alpha \cdot A_{j} \cdot k_{j}^{\alpha-1} \\
k_{j} & =\frac{\beta^{\theta}}{\beta^{\theta}+r_{j}^{1-\theta}} \cdot\left(\varepsilon \cdot w_{j}+\frac{n_{j}}{g}\right) .
\end{aligned}
$$

In particular, wages and the capital stock are increasing in the discounted value of bubble creation, whereas the opposite is true for the return on capital.

It thus follows that, in these deterministic allocations, we can express the steady-state welfare of entrepreneurs in $j$ as:

$$
U_{j}^{E}\left(\frac{n_{j}}{g}\right)=\left[\frac{r_{j}^{1-\theta}}{\beta^{\theta}+r_{j}^{1-\theta}} \cdot\left(\varepsilon \cdot w_{j}+\frac{n_{j}}{g}\right)\right]^{1-1 / \theta}+\beta \cdot\left[r_{j} \cdot \frac{\beta^{\theta}}{\beta^{\theta}+r_{j}^{1-\theta}} \cdot\left(\varepsilon \cdot w_{j}+\frac{n_{j}}{g}\right)\right]^{1-1 / \theta}
$$

The funds for investment and consumption available to entrepreneurs equal their wage plus the discounted value of bubble creation. A fraction of these funds is consumed during youth. The rest is invested in capital, the return of which is the entrepreneurs' only source of income during old age. Note therefore that the welfare of entrepreneurs depends only on the wage, the return to capital, and the discounted value of bubble creation. Since both the wage and the return to capital depend in turn on the discounted value of bubble creation, the welfare of entrepreneurs ultimately depends on this variable. It can be shown, moreover, that this relationship is non-decreasing. 
Finally, in these allocations, we can also express the steady-state welfare of savers in $j$ as follows,

$$
U_{j}^{S}\left(g, \frac{n_{j}}{g}\right)=\left[\frac{g^{1-\theta}}{\beta^{\theta}+g^{1-\theta}} \cdot(1-\varepsilon) \cdot w_{j}\right]^{1-1 / \theta}+\beta \cdot\left[g \cdot \frac{\beta^{\theta}}{\beta^{\theta}+g^{1-\theta}} \cdot(1-\varepsilon) \cdot w_{j}\right]^{1-1 / \theta}
$$

During youth, savers supply their labor in exchange for a wage: of this labor income, a fraction is consumed during youth whereas the rest is lent in the global credit market at an interest rate of $g$. Thus, the welfare of savers in $j$ is monotonically increasing in the country's wage and thus in its discounted value of bubble creation. Differently from entrepreneurs, though, the welfare of savers also increases monotonically in $g$, which reflects the returns on their savings.

We are now ready to define the set of Pareto optimal bubbles in steady state.

Definition 5 A bubble $\left\{g, n_{j}\right\}_{j \in J}$ is Pareto optimal if it satisfies

$$
\left\{g, n_{j}\right\}_{j \in J} \in \arg \max \sum_{j}\left[\lambda_{j}^{E} \cdot U_{j}^{E}\left(\frac{n_{j}}{g}\right)+\lambda_{j}^{S} \cdot U_{j}^{S}\left(g, \frac{n_{j}}{g}\right)\right]
$$

subject to Equations (50)-(54), and

$$
c^{d}\left(\left\{g, n_{j}\right\}_{j \in J}\right) \equiv \frac{\sum_{j} \frac{n_{j}}{g}}{\sum_{j} A_{j} \cdot k_{j}^{\alpha}}=(1-g) \cdot \frac{\beta^{\theta}}{\beta^{\theta}+g^{1-\theta}} \cdot(1-\varepsilon) \cdot(1-\alpha) \equiv c^{s}(g)
$$

for some $\lambda_{j}^{E}, \lambda_{j}^{S} \geq 0, j \in J$.

Strictly speaking, these bubbles are constrained Pareto optimal because they maximize welfare subject to the collateral constraints. This is implicit in Equation (56), which guarantees that the credit market clears given the discounted value of bubble creation in all countries. The left-hand side of the expression denotes the global demand of credit for investment as a share of world output. We denote it by $c^{d}\left(\left\{g, n_{j}\right\}_{j \in J}\right)$, and it is equal to the discounted value of global bubble divided by world output. It can be shown that it is decreasing in $g$. The right-hand side of Equation (56) denotes instead the supply of credit for investment as a share of world output. It is equal to the fraction of world output that is perceived by savers in the form of wages, times their savings rate: of these funds, though, only a fraction $1-g$ is available to finance new investment after existing bubbles have been purchased. Thus, as we discussed in the context of the deterministic example in section $2, c^{s}(g)$ is backward bending and it is maximized at an interior interest rate $g^{*} \in(0,1)$.

The previous discussion implies that, given any interest rate $g<g^{*}$, there exists an alternative 
interest rate $g^{\prime}>g^{*}$ such that $c^{s}(g)=c^{s}\left(g^{\prime}\right)$. But we can say more than this for any two such interest rates $g$ and $g^{\prime}$. Given any bubble $\left\{g, n_{j}\right\}_{j \in J}$ with $c^{d}\left(\left\{g, n_{j}\right\}_{j \in J}\right)=c^{s}(g)$, there exists an alternative bubble $\left\{g^{\prime}, n_{j}^{\prime}\right\}_{j \in J}$ with $n_{j}^{\prime}=n_{j} \cdot \frac{g^{\prime}}{g}$ for all $j \in J$ that satisfies $c^{d}\left(\left\{g^{\prime}, n_{j}^{\prime}\right\}_{j \in J}\right)=c^{s}\left(g^{\prime}\right)=c^{s}(g)$. The low interest rate bubble corresponds to a low savings rate and a low level of bubble creation $\sum_{j} n_{j}$, and it has low crowding-out and crowding-in effects; the high interest rate bubble corresponds instead to a high savings rate and a high level of bubble creation $\sum_{j} n_{j}^{\prime}$, and it has high crowdingout and crowding-in effects. The net of the crowding-in and crowding-out effects is exactly the same in both bubbles, however, which yield the same level of investment and output. This implies that entrepreneurs are indifferent between them while savers strictly prefer the high-interest rate bubble, which leads to our first result:

Proposition 2 Any Pareto optimal bubble $\left\{g, n_{j}\right\}_{j \in J}$ satisfies $g \geq g^{*}$.

Proof. Follows from previous discussion.

Given this result, what is the optimal amount of bubble creation, and thus of credit? As we now show, this depends on the relative valuation that the planner assigns to savers and entrepreneurs.

Proposition 3 Consider the subset of Pareto optimal bubbles associated with weights $\lambda_{j}^{E}>0$ and $\lambda_{j}^{S}=0$ for all $j \in J$. All bubbles $\left\{g, n_{j}\right\}_{j \in J}$ in that set satisfy $c^{d}\left(\left\{g, n_{j}\right\}_{j \in J}\right)=c^{s}\left(g^{*}\right)$.

Proof. Suppose, by contradiction, that there exists a Pareto optimal bubble $\left\{g, n_{j}\right\}_{j \in J}$ associated with weights $\lambda_{j}^{E}>0$ and $\lambda_{j}^{S}=0$ for which $g>g^{*}$, i.e., $c^{d}\left(\left\{g, n_{j}\right\}_{j \in J}\right)=c^{s}(g)<c^{s}\left(g^{*}\right)$. We know that there exists an alternative bubble $\left\{g^{*}, n_{j}^{\prime}\right\}_{j \in J}$, for $n_{j}^{\prime}=n_{j} \cdot \frac{g^{*}}{g}$, such that $U_{j}^{E}\left(\frac{n_{j}}{g}\right)=$ $U_{j}^{E}\left(\frac{n_{j}^{\prime}}{g^{*}}\right)$ for all $j \in J$ and $c^{d}\left(\left\{g^{*}, n_{j}^{\prime}\right\}_{j \in J}\right)=c^{d}\left(\left\{g, n_{j}\right\}_{j \in J}\right)<c^{s}\left(g^{*}\right)$. But then, it is possible to find $\varepsilon_{j} \geq 0$ for $j \in J$ such that the bubble $\left\{g^{*}, n_{j}^{\prime}+\varepsilon_{j}\right\}_{j \in J}$ satisfies $c^{d}\left(\left\{g^{*}, n_{j}^{\prime}+\varepsilon_{j}\right\}_{j \in J}\right)=$ $c^{s}\left(g^{*}\right)$ and $U_{j}^{E}\left(\frac{n_{j}^{\prime}+\varepsilon}{g^{*}}\right) \geq U_{j}^{E}\left(\frac{n_{j}^{\prime}}{g^{*}}\right)$ for all $j \in J$ with at least one strict inequality. Thus, the original bubble $\left\{g, n_{j}\right\}_{j \in J}$ is not Pareto optimal given weights $\lambda_{j}^{E}>0$ and $\lambda_{j}^{S}=0$ for all $j \in J$.

Proposition 3 provides an intuitive result. A planner that values only the welfare of entrepreneurs will maximize credit and investment as a share of global output, i.e., it will set $g=g^{*}$. Naturally, there are many different bubbles $\left\{g^{*}, n_{j}\right\}_{j \in J}$ that satisfy this condition, all of which differ in absolute levels of investment and output. If the planner places a high relative weight on entrepreneurs from one particular country, for instance, or if entrepreneurs in any given country are particularly poor, it will choose allocations in which these entrepreneurs receive a disproportionate 
share of the global bubble. To the extent that it is not guided by productive efficiency, the resulting allocation of investment will fail to maximize global output. Nonetheless, regardless of the actual weights $\lambda_{j}^{E}$, the share of output that is used to finance investment will always be set at its maximum value $c^{s}\left(g^{*}\right)$.

One particular case of interest is that of $\theta \rightarrow \infty$ (i.e., utility is linear in consumption) and $\lambda_{j}^{E}=\lambda$ for all $j$. In this case, the planner has no incentives to redistribute resources across entrepreneurs because both their marginal utility and their Pareto weights are constant across countries. ${ }^{15}$ Thus, the objective of the planner problem becomes to maximize world output, which is attained by setting

$$
n_{j}=g^{*} \cdot A_{j}^{\frac{1}{1-\alpha}} \cdot\left[\left(\frac{\alpha}{r^{*}}\right)^{\frac{1}{1-\alpha}}-(1-\alpha) \cdot\left(\frac{\alpha}{r^{*}}\right)^{\frac{\alpha}{1-\alpha}}\right] \text { for } j \in J
$$

where $r^{*}$ is implicitly defined by

$$
r^{*}=\frac{\alpha}{(1-\alpha) \cdot\left(\varepsilon+(1-\varepsilon) \cdot\left(1-\frac{1}{\beta}\right)\right)} .
$$

This set of bubbles guarantees that $k_{j}=\left(\frac{\alpha \cdot A_{j}}{r^{*}}\right)^{\frac{1}{1-\alpha}}$, and thus $r_{j}=r^{*}$, for $j \in J$.

When the planner values only the welfare of entrepreneurs, it benefits them by setting $g=g^{*}$ so that, for a given distribution of the bubble, credit and investment are maximized. When the planner also values the welfare of savers, however, it may be willing to forego some output in exchange for a higher interest rate to benefit savers.

To see this, we can consider a symmetric world with $A_{j}=A$ for all $j$ and characterize the Pareto optimal bubbles associated with weights $\lambda_{j}^{E}=0$ and $\lambda_{j}^{S}=1$ for all $j$. In this case, it can be shown that any such bubble $\{g, n\}_{j \in J}$ is symmetric and has $g>g^{*}$. Symmetry follows naturally from the environment. To see why $g>g^{*}$, we can fully differentiate the market clearing condition of Equation (56) to obtain the elasticity of the equilibrium interest rate with respect to $n$, i.e. with respect to a symmetric increase in bubble creation in all countries. It turns out that, when evaluated at $g^{*}$, this elasticity is exactly equal to one. ${ }^{16}$ This implies that, locally, increases in $n$ raise the interest rate without affecting investment or output in any country, i.e., they have no first-order effects on the welfare of entrepreneurs but they strictly raise the welfare of savers.

\footnotetext{
${ }^{15}$ This particular case is thoroughly studied by Martin and Ventura (forthcoming) for the case of a single country.

${ }^{16}$ Intuitively, the supply of credit for investment is maximized at $g^{*}$. Thus, local and simultaneous changes in bubble creation in all countries are fully offset by equal changes in $g$, and they have no effect on the supply of credit for investment.
} 
Hence, any Pareto optimal bubble associated with weights $\lambda_{j}^{E}=0$ and $\lambda_{j}^{S}=1$ for all $j$ must have $g>g^{*}$.

This example shows that if a planner values the welfare of savers, it may find it optimal to choose a bubble $\{g, n\}_{j \in J}$ such that $g>g^{*}$ and $c^{d}\left(\{g, n\}_{j \in J}\right)<c^{s}\left(g^{*}\right)$. Naturally, the extent to which the planner is willing to sacrifice investment in exchange for a higher interest rate depends on both, the elasticity of the interest rate with respect to bubble creation and the relative weights assigned to savers and entrepreneurs in the social welfare function. Whatever gap there is between the planner's chosen interest rate $g$ and the interest rate that maximizes credit $g^{*}$, this gap will be increasing in the weights $\left\{\lambda_{j}^{S}\right\}_{j \in J}$ relative to $\left\{\lambda_{j}^{E}\right\}_{j \in J}$.

This completes our discussion of the set of Pareto optimal allocations. We now turn to the bubbles that are actually implemented by governments.

\subsection{Cooperative and non-cooperative policy}

Consider now that the bubble $\left\{g, n_{j}\right\}_{j \in J}$ results from the choices of individual governments, each of which maximizes

$$
\gamma_{j}^{E} \cdot U_{j}^{E}\left(\frac{n_{j}}{g}\right)+\gamma_{j}^{S} \cdot U_{j}^{S}\left(g, \frac{n_{j}}{g}\right)
$$

for $\gamma_{j}^{E}, \gamma_{j}^{S} \geq 0$. How does the equilibrium allocation that results from government choices differ from the set of Pareto optimal allocations characterized above? The answer to this question depends on how the equilibrium is defined. In what follows, we characterize both a cooperative equilibrium, in which governments choose the combination of policies that maximizes their joint welfare, and a non-cooperative equilibrium, in which each government chooses the policy that maximizes its own welfare while taking the policies of the other governments as given.

The cooperative equilibrium is defined as follows:

Definition 6 A cooperative equilibrium of the global economy is characterized by a bubble $\left\{g^{c}, n_{j}^{c}\right\}_{j \in J}$ that satisfies

$$
\left\{g^{c}, n_{j}^{c}\right\}_{j \in J} \in \arg \max \sum_{j} v_{j} \cdot\left[\gamma_{j}^{E} \cdot U_{j}^{E}\left(\frac{n_{j}}{g}\right)+\gamma_{j}^{S} \cdot U_{j}^{S}\left(g, \frac{n_{j}}{g}\right)\right]
$$

for $v_{j} \geq 0$, subject to Equations (50)-(54), and

$$
c^{d}\left(\left\{g, n_{j}\right\}_{j \in J}\right) \equiv \frac{\sum_{j} \frac{n_{j}}{g}}{\sum_{j} A_{j} \cdot k_{j}^{\alpha}}=(1-g) \cdot \frac{\beta^{\theta}}{\beta^{\theta}+g^{1-\theta}} \cdot(1-\varepsilon) \cdot(1-\alpha) \equiv c^{s}(g) .
$$


A cooperative equilibrium is thus defined as the set of policies that maximize the weighted sum of country welfare, where each country is given a weight $v_{j} \geq 0$. These country-weights could reflect the ability of countries to bias global outcomes in their favor due, for instance, to political, economical, or lobbying power. Within each country, $\gamma_{j}^{E}$ and $\gamma_{j}^{S}$ reflect the weights given to entrepreneurs and savers by their corresponding government. Whatever these weights, it is immediate from comparing Definitions 5 and 6 that the cooperative equilibrium is Pareto optimal. In particular, it corresponds to the solution of the planner problem when $\lambda_{j}^{E}=v_{j} \cdot \gamma_{j}^{E}$ and $\lambda_{j}^{S}=v_{j} \cdot \gamma_{j}^{S}$ for all $j$. From the discussion of the previous section, we can therefore establish the following result:

Proposition 4 Any cooperative equilibrium $\left\{g^{c}, n_{j}^{c}\right\}_{j \in J}$ is Pareto optimal.

Proof. Follows directly from Definitions 5 and 6 .

In the non-cooperative equilibrium, governments instead try to maximize their own welfare while taking the policies of the other countries as given. Formally:

Definition 7 A non-cooperative equilibrium of the global economy is characterized by a set of interest rate and bubbles $\left\{g^{n c}, n_{j}^{n c}\right\}_{j \in J}$ that satisfies

$$
\left\{g^{n c}, n_{j}^{n c}\right\} \in \arg \max \left[\gamma_{j}^{E} \cdot U_{j}^{E}\left(\frac{n_{j}}{g}\right)+\gamma_{j}^{S} \cdot U_{j}^{S}\left(g, \frac{n_{j}}{g}\right)\right] \text { for } j \in J
$$

subject to Equations (50)-(54), and

$$
c^{d}\left(\left\{g, n_{j}\right\}_{j \in J}\right) \equiv \frac{\sum_{j} \frac{n_{j}}{g}}{\sum_{j} A_{j} \cdot k_{j}^{\alpha}}=(1-g) \cdot \frac{\beta^{\theta}}{\beta^{\theta}+g^{1-\theta}} \cdot(1-\varepsilon) \cdot(1-\alpha) \equiv c^{s}(g) .
$$

Definition 7 shows that the reason for which the non-cooperative equilibrium differs from the cooperative one is that, in the former, governments do not internalize the spillover effects of their policy choices. When the government sets $n_{j}$, it affects both the capital stock in its economy and the global interest rate. This has a direct effect on the welfare of its own savers and entrepreneurs, but also on the welfare of savers and entrepreneurs in all other countries. In the cooperative solution, it follows from Equation (57) that this cross-border effect is internalized; in the non-cooperative solution, it follows from Equation (59) that it is not. This implies that, generically, non-cooperative equilibria are not Pareto optimal. The following proposition establishes this result formally.

Proposition 5 Non-cooperative equilibria $\left\{g^{n c}, n_{j}^{n c}\right\}_{j \in J}$ are generically not Pareto optimal. 
Proof. To be a non-cooperative equilibrium, a bubble must satisfy

$$
\gamma_{j}^{E} \cdot\left(\frac{\partial U_{j}^{E}}{\partial n_{j}}+\frac{\partial U_{j}^{E}}{\partial g} \cdot \frac{d g}{d n_{j}}\right)+\gamma_{j}^{S} \cdot\left(\frac{\partial U_{j}^{S}}{\partial n_{j}}+\frac{\partial U_{j}^{S}}{\partial g} \cdot \frac{d g}{d n_{j}}\right)=0
$$

for all $j$. To be Pareto optimal a bubble must instead satisfy

$$
\lambda_{j}^{E} \cdot \frac{\partial U_{j}^{E}}{\partial n_{j}}+\sum_{j^{\prime} \in J} \lambda_{j^{\prime}}^{E} \cdot \frac{\partial U_{j^{\prime}}^{E}}{\partial g} \cdot \frac{d g}{d n_{j}}+\lambda_{j}^{S} \cdot \frac{\partial U_{j}^{S}}{\partial n_{j}}+\sum_{j^{\prime} \in J} \lambda_{j^{\prime}}^{S} \cdot \frac{\partial U_{j^{\prime}}^{S}}{\partial g} \cdot \frac{d g}{d n_{j}}=0
$$

for some weights $\left\{\lambda_{j}^{S}, \lambda_{j}^{E}\right\}_{j \in J}$ and for all $j$. The difference between both expressions is that the condition for Pareto optimality takes into account how the choice of $n_{j}$ affects both entrepreneurs and savers in countries $j^{\prime} \neq j$. In the case of entrepreneurs in $j^{\prime}, \frac{\partial U_{j^{\prime}}^{E}}{\partial g}<0$ because, given $n_{j^{\prime}}^{n c}$, increases in $g$ reduce investment and the capital stock. In the case of savers in $j^{\prime}$, the sign of $\frac{\partial U_{j^{\prime}}^{S}}{\partial g}$ is ambiguous: on the one hand, increases in $g$ reduce the capital stock in $j^{\prime}$ thereby hurting savers; on the other hand, increases in $g$ raise the return to savings. Depending on which effect dominates, governments in a non-cooperative equilibrium will have incentives to choose bubbles that are too large or too small relative to the Pareto optimal bubbles.

Proposition 5 says that, generically, non-cooperative equilibria will lead to Pareto inferior bubbles. It does not, however, allow us to say whether non-cooperative equilibria will lead to bubbles that are in general too large or too small. There is however a strong presumption that it will lead to suboptimally large bubbles, i.e., governments have an incentive to subsidize credit excessively and the equilibrium is characterized by a high interest rate and depressed levels of investment and output relative to the Pareto optimal bubble. There are two situations in which this presumption is likely to be true.

The first situation is when governments place a high value on the welfare of their entrepreneurs (or equivalently, on the level of domestic output): in the particular case in which governments only value the welfare of entrepreneurs (i.e., $\lambda_{j}^{S}=0$ for $j \in J$ ), it can be formally shown that $g>g^{*}$ in any non-cooperative equilibrium. The reason, of course, is that each government chooses to subsidize domestic credit excessively without taking into account that this expansion raises the world interest rate and reduces credit abroad.

The second situation is when countries are small relative to the world economy, so that their governments internalize only a small fraction of their bubbles' crowding-out effects and bubble 
creation is consequently too high. In the particular case in which countries are arbitrarily small, all governments want their respective bubbles to be arbitrarily large. ${ }^{17}$

This analysis should not give the impression that the type of credit management policies analyzed here are undesirable if set in a non-cooperative fashion. They do create collateral and expand world output and, equally important, they fully stabilize the economy from investor sentiment shocks. The analysis does suggest, though, that these gains can be even larger if the policies are set in a cooperative fashion.

\section{Concluding remarks}

We live in a world of deep financial integration, low interest rates, and frequent credit booms and busts. In this paper, we have developed a framework to think about these three stylized facts as part of a general narrative. In our model, low interest rates are the result of weak enforcement institutions, which limit collateral and thus credit and investment in the global economy. For simplicity, we have assumed throughout that enforcement institutions are equally weak in all countries: nothing substantial would change, however, if we assumed that they are particularly weak in developing countries. In this case, the decline in the world interest rate could be attributed to the latter's increasing financial integration with the global economy.

Our model shows that low interest rates create the conditions for asset bubbles to arise, which in turn give rise to credit booms and busts. When a bubble raises the market value of assets in an economy, it relaxes borrowing constraints and fuels a credit boom that attracts foreign capital and expands investment and economic growth. The effects of this expansion propagate across the world economy through the world interest rate, which increases for the rest of the world due to the higher demand for credit. If the boom extends in time, though, the bubble grows and so does its crowding-out effect: in the long-run, this effect can be so strong that the bubble contracts economic activity relative to its fundamental equilibrium. Of course, credit booms sustained by asset bubbles ultimately rest on expectations or investor sentiment, which are prone to sudden shifts. When this happens, the boom turns into a credit bust and asset prices and intermediation fall as capital flows abroad.

This general description of credit booms and busts seems quite conventional. But it turns the

\footnotetext{
${ }^{17}$ This does not mean, of course, that the non-cooperative equilibrium will always lead to excessively large bubbles. One can constract counterexamples, when goverments value the welfare of savers highly, in which nonñcoopeative bubble creation is excessively low.
} 
standard perception of the link between asset prices, investment and capital flows on its head. The conventional way of thinking about these episodes is that, in any given country, investment responds to increases in productivity: it is this increase in investment that raises credit, capital inflows and asset prices. Our model provides a different way of interpreting these phenomena. In a global economy characterized by low interest rates, it may very well be it is changes in expectations or investor sentiment that drive changes in asset prices, which in turn translate into fluctuations in credit, investment and capital inflows. It is bubbles that provide collateral and sustain capital flows, instead of the other way around. Insofar as investor sentiment can change abruptly and independently of economic fundamentals, our model therefore provides a rationale for the incidence of credit booms and busts in a low-interest world.

By providing an alternative view of credit booms and busts, our model also provides a different role for policy. In particular, it shows that a global planner should adopt a policy of "leaningagainst-investor-sentiment", taxing credit in those times and countries where credit is excessive and subsidizing it elsewhere. An important characteristic of this policy is that it is expectationally robust, in the sense that it isolates the world economy from fluctuations in investor sentiment. This policy may be hard to implement in a decentralized fashion, though, as individual countries are unlikely to internalize the effects of their policies on the world interest rate.

Of course, our model provides a first approach to many of these questions. One important issue that we have left aside is the study of policy, both at the global and at the country level, in a more heterogenous world. What would change if countries differed in the credibility of their institutions, for instance, and thus in their ability to implement policy? Is it reasonable to assume that larger and more credible countries will be better able to adopt policies like the one studied here, thereby capturing the rents that arise from hosting bubbles in a low-interest global economy? And what if countries produced differentiated goods? Bubbles would then be transmitted not only through the interest rate, but also through the terms of trade. How would our analysis of optimal policy change in such an environment? These are fascinating questions that provide an exciting avenue for future research.

\section{References}

[1] Alesina, A., M. De Broeck, A. Prati, G. Tabellini, and M. Obstfeld (1992), "Default risk on government debt in OECD countries," Economic Policy, pp. 428-463. 
[2] Aoki, K., Benigno, G. and N. Kiyotaki (2010), "Adjusting to Capital Account Liberalization", mimeo, LSE.

[3] Basco, Sergi (2014), "Globalization and financial development: A model of the Dot-Com and the Housing Bubbles", Journal of International Economics, 92(1), 78-94.

[4] Bernanke, B. (2009), "Financial reform to address systemic risk," Speech at the Council on Foreign Relations, Washington, D.C, 10 March.

[5] Boyd, John, and B. Smith (1997), "Capital Market Imperfections, International Credit Markets, and Nonconvergence", Journal of Economic Theory, 335-64.

[6] Caballero, R., E. Farhi and P.O. Gourinchas (2008), "An Equilibrium Model of 'Global Imbalances' and Low Interest Rates", American Economic Review, 98 (1), 358-393.

[7] Caballero, R. and A. Krishnamurthy (2006), "Bubbles and Capital Flow Volatility: Causes and Risk Management", Journal of Monetary Economics 53(1), 33-53.

[8] Claessens, S., A. Kose and M. Terrones (2011), "Financial Cycles: What? How? When?", NBER International Seminar on Macroeconomics, University of Chicago Press, 7(1), 303 344.

[9] Cole, H. and T. Kehoe (2000), "Self-Fulfilling Debt Crises," Review of Economic Studies, Wiley Blackwell, vol. 67(1), 91-116.

[10] Dell'Ariccia, G., D. Igan, L. Laeven and H. Tong, with B. Bakker and J. Vandenbussche (2012), "Policies for Macrofinancial Stability: How to Deal with Credit Booms", IMF Staff Discussion Note, SDN 12/06.

[11] Dell'Ariccia, G., D. Igan and L. Laeven (2012), "Credit Booms and Lending Standards: Evidence from the Subprime Mortgage Market", Journal of Money, Credit, and Banking 44(2-3), $367-384 .$.

[12] Dell'Ariccia, G. and R. Marquez (2006), "Lending Booms and Lending Standards", The Journal of Finance 51(5), 2511-2546.

[13] Economist, The (2009), "When a flow becomes a flood", January 22.

[14] Farhi, E. and J. Tirole (2011), "Bubbly Liquidity", Review of Economic Studies 79, 678-706. 
[15] Gertler, M., and K. Rogoff (1990), "North-South lending and endogenous domestic capital market inefficiencies", Journal of Monetary Economics 26, 245-266.

[16] Gorton, G. and P. He (2008), "Bank Credit Cycles", Review of Economic Studies 75(4), 11811214.

[17] Gourinchas, P.O., R. Valdes and O. Landerretche (2001), "Lending Booms: Latin America and the World", Economia 1(2), 47-99.

[18] Krugman, P (2009): "Revenge of the glut," The New York Times, 1 March.

[19] Kraay, A. and J. Ventura (2007), "The Dot-Com Bubble, the Bush Deficits, and the US Current Account" in R. Clarida (ed.), G7 Current Account Imbalances: Sustainability and Adjustment, The University of Chicago Press.

[20] Lorenzoni, G. and I. Werning (2014), "“'Slow Moving Debt Crises", mimeo, MIT.

[21] Martin, A. (2008), "Endogenous Credit Cycles", mimeo, CREI.

[22] Martin, A. and J. Ventura (2011), "Theoretical Notes on Bubbles and the Current Crisis", IMF Economic Review 59, 6-40.

[23] Martin, A. and J. Ventura (2012), "Economic Growth with Bubbles", American Economic Review 102, 3033-3058.

[24] Martin, A. and J. Ventura (forthcoming), "Managing Credit Bubbles", Journal of the European Economic Association.

[25] Matsuyama, K. (2004), "Financial market globalization, symmetry-breaking and endogenous inequality of nations", Econometrica 72 (3), 853-884.

[26] Matsuyama, K. (2007), "Credit Traps and Credit Cycles", American Economic Review 97(1), 503-516.

[27] Mendoza, E., J. Rios-Rull and V. Quadrini (2009), "Financial Integration, Financial Deepness and Global Imbalances", Journal of Political Economy 117 (3), 371-410

[28] Mendoza, E. and M. Terrones (2012), "An Anatomy of Credit Booms and their Demise", WP 18379, NBER. 
[29] Miao, J. and P. Wang (2011), "Bubbles and Credit Constraints", mimeo, Boston University.

[30] Portes, R (2009): "Global imbalances", in M. Dewatripont, X. Freixas, and R. Portes (eds), Macroeconomic stability and financial regulation: Key issues for the G20, London, CEPR.

[31] Ruckes, M. (2004), "Bank Competition and Credit Standards", The Review of Financial Studies 17(4), 1073-1102.

[32] Samuelson, P. (1958), "An Exact Consumption-loan Model of Interest with or without the Social Contrivance of Money", Journal of Political Economy 66, 467-482.

[33] Schularick, M. and A. Taylor (2012), "Credit Booms Gone Bust: Monetary Policy, Leverage Cycles and Financial Crises, 1870-2008", American Economic Review 102(2), 1029-1061.

[34] Ventura, J. (2011), "Bubbles and Capital Flows", Journal of Economic Theory 147 (2), 738758. 


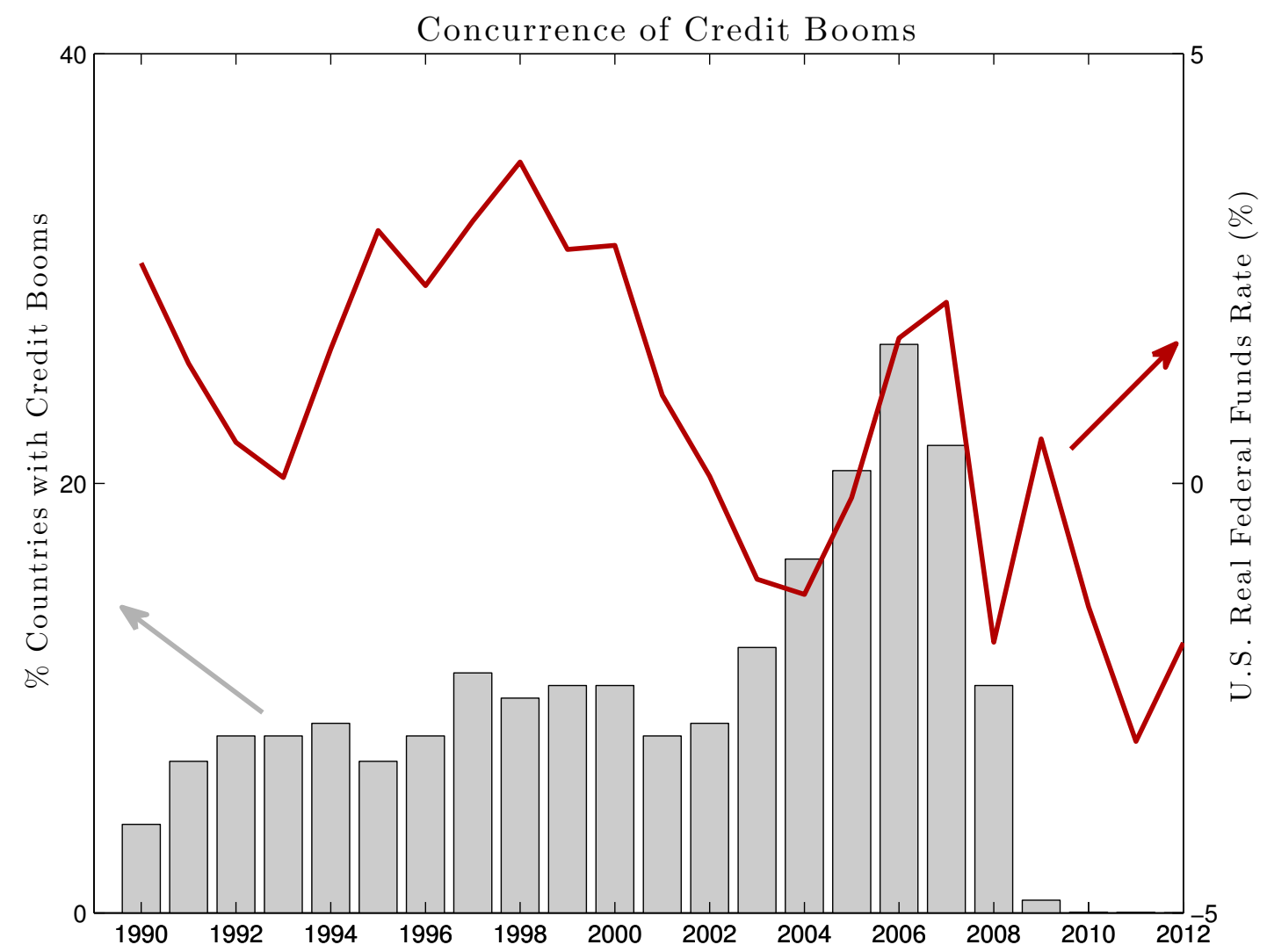

Figure 1 : Credit booms are identified by comparing the credit-to-GDP ratio in a given year to a rolling, country-specific, cubic trend estimated over a 10-year period (see Dell'Ariccia et al. [2012]). In particular, a credit booms occurs if the deviation from trend is greater than 1.5 times its standard deviation and the annual growth rate of the credit-to-GDP ratio exceeds 10 percent; or if the growth rate of the credit-to-GDP ratio exceeds 20 percent. There is a total of 170 countries in the sample. 

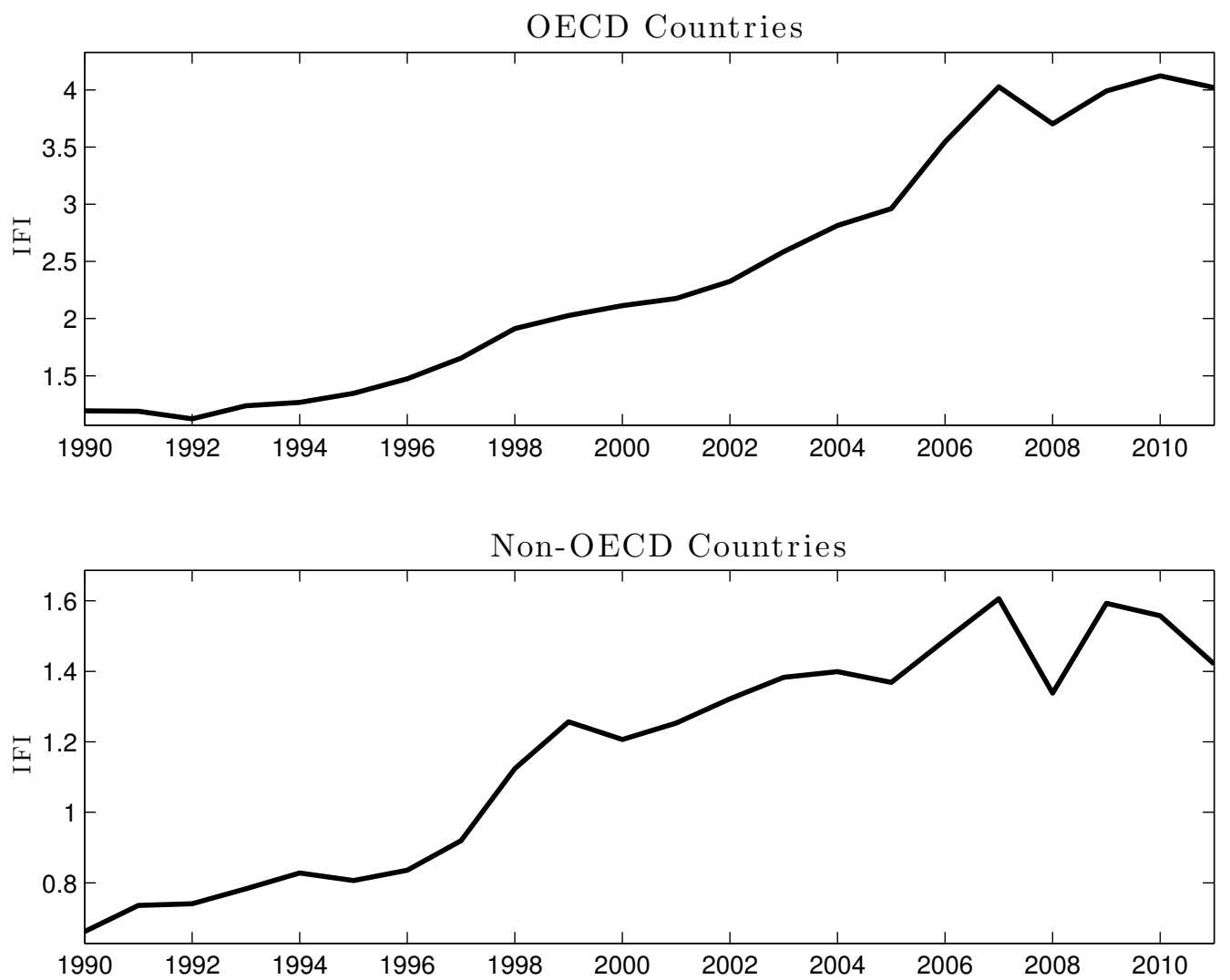

Figure 2 : IFI is the sum foreign assets and liabilities scaled by GDP (see Lane [2012]). We report the aggregate IFI ratio for OECD and Non-OECD countries. Data are taken from the Lane and Milesi-Feretti database and low-income countries, oil producers and countries with population less than one million were excluded. 